CONF-9010185--4

DE91 001629

\title{
Heavy-Section Steel Technology Program Overview
}

\author{
W. E. Penneli \\ Engineering Technology Division \\ Oak Ridge National Laboratory \\ Oak Ridge, Tennesses
}
To be presented at the 18th Water Reactor Safety Information Meeting Holiday Inn Crowne Plaza Hotel, Rockville, Maryland
October 22-24, 1990.

\section{DISCLAIMER}

\begin{abstract}
This report was prepared as an account of work spousured by an agency of the United States Government. Neither the United States Government nor any agency thereof. nor any of their employees, makes any warranty, express or implied, or assumes any legal liability or responsibility for the accuracy, completeness, or usefulness of any information, apparatus, product, or process disclosed, or represents that its use would not infri.ge privateiy owned rights. Reference herein to any specific commercial product, process, or service by trade name, trademark, manufacturer, or otherwise does not necessarily constitute or imply its endorsement, recommendation, or favoring by the United States Government or any agency thereof. The views and opinions of authurs expressed herein do not necessarily state or reflect those of the United States Government or any agency thereof.
\end{abstract}

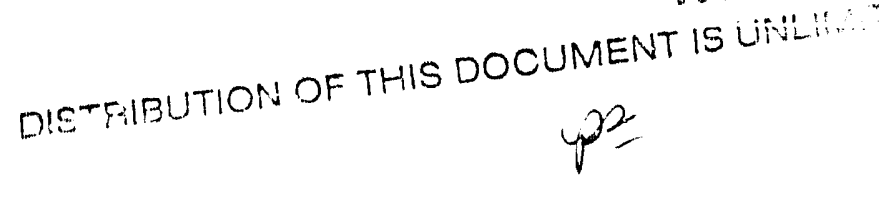




\title{
Heavy-Section Steel Technology Program Overview*
}

\author{
W. E. Pennell \\ Engineering Technology Division \\ Oak Ridge National Laboratory \\ Oak Ridge, Tennessee
}

\begin{abstract}
This paper presents a status review of ongoing HSST program tasks aimed at refining the technology used in analysis of reactor pressure vessel fracture margins under pressurized thermal-shock (PTS) loading. Specific fracture-technology issues addressed include vessel flaw density and disiribution, shallow flaws, fracture-toughness data transfer, circumferential cracks, ductile tearing and the influence of low-tearing toughness in stainless steei cladding. Preliminary results from the analysis and test programs are presented, together with interim assessments of their potential impact on a reactor vessel PTS analysis.
\end{abstract}

\section{Introduction}

Technology required for the accurate assessment of fracture-prevention margins in commercial nuclear reactor pressure vessels has been under continuous development for the past twenty-five years. The Nuclear Regulatory Commission (NRC)-funded Heavy-Section Steel Technology (HSST) Program was created to act as a focus for this essential safety-related development activity. The HSST Program, which is managed by Oak Ridge National Laboratory (ORNL), integrates input from a broad spectrum of national and international fracture mechanics research organizations to achieve the program objectives.

Early emphasis in the HSST Program was on development of fracture- mechanics methodology, and the associated materials fracture-toughness data base, for nuclear reactor pressure vessels. Results from this phase of the program were used to support the generation of regulatory instruments and national consensus Codes and Standards. This was followed by a phase of fracture technology validation using large-scale fracture mechanics tests with test articles fabricated from prototypical heavy-section reactor pressure vessel (RPV) steels. Results from these tests, and similar tests conducted by overseas fracture mechanics research organizations, identified a number of RPV fracture-technology issues.

In a paraliel development, the growing body of surveillance program data from commercial nuclear power plants provided evidence that some reactor pressure vessels were accumulating irracliation damage at a rate higher than previously anticipated (Refs. $1 \& 2$ ).

Data from materials-irradiation research reactors provided identification of additional previously unanticipated irradiation damage trends (Refs. 3,4 and 5). The net effect of these developments

\footnotetext{
*Research sponsored by the Office of Nuclear Regulatory Research, U.S. Nuclear Regulatory Commission under Interagency Agreement 1886-8011-9B with the U.S. Department of Encrgy under Contract DE-AC05-84OR21400 with Martin Marietla Energy Systems, Inc.
} 
was to require that reactor pressure vessel fracture-margin-safety assessments be performed in the near-term for a number of commercial nuclear power plants.

Pressurized-thermal-shock (PTS) has emerged as a loading condition of primary concern for reactor pressure vessel fracture-margin-safety assessments. Fracture technology issues with special significance to PTS analysis are of particular interest at this time. The focus of this paper is on ongoing HSST Program research and development (R\&D) activities which relate directly to PTS analysis fracture issues. PTS R\&D is an important element of the HSST program which is structured to address a broad spectrum of current fracture mechanics related licensing issues.

\section{$2 \quad$ Background}

A review of iesults from prior PTS analysis is useful in that it provides a basis for assessing the sensitivity of the analysis results to specific input parameters. The U.S. Nuclear Regulatory Guide for PTS analyses (Ref. 6) identifies the analysis of the H. B. Robinson nuclear power plant (Ref. 7) as a suitable generic model for PTS analyses. Results from that analysis therefore provide a suitable basis for the PTS-analysis input-parameter-sensitivity review.

PTS analysis of the reactor vessel for the H. B. Robinson nuclear plant did not predict sufficient through-wall fractures to provide an adequate demonstration of the PTS-analysis technology. To overcome this problem, the analysis of Ref. 7 also considered a hypothetical reactor vessel with weld-metal copper and nickel contents increased so as to produce accelerated irradiation embrittlement. The analysis also considered a hypothetical distribution of flaws in the reactor vessel wall. This vessel was designated the HBR-HYPO vessel. Results considered in this review of analysis experience are all for the HBR-HYPO reactor vessel.

The acceptance limit for a PTS-safety analy'sis is set in Ref. 6 in terms of a reactor vessel throughwall crack-penetration mean frequency which may not exceed $5 \times 10^{-6}$ per reactor year. Analysis of the plant response to abnormal configurations and operating conditions leads to the identification of a broad range of transients which must be evaluated in the probabilistic PTS analysis. A small subset of these transients however account for a majority of the predictions of through-wall cracking. Transients in this category are termed the dominant transients. In the case of the HBRHYPO vessel PTS analysis, 6 dominant transients accounted for $75 \%$ of all of the predictions of through-wall cracking. These transients, are listed in Table 1. Results from the analysis of the vessel response to these dominant transients provide the basis for this review.

Dominant transients listed in Table 1 are all the result of postulated failure of secondary side valves following a reactor trip. Valves involved are the steam power-operated-relief-valves (STM PORVs) and the steam dump-valves (SDV). These valves permit removal of heat from the reactor system in the event of a sudden loss of turbine load by dumping steam to the atmosphere (STM PORYs) or to the condensers (SDV). In the stuck-open condition, blowdown of the affected steam generators occurs, with an associated rapid removal of heat from the reactor primary coolant system.

Characteristics of two of the dominant transients for the HBR-HYPO reactor vessel are illustrated in Fig 1. These transients were selected because they bound the range of pressure-temperature time-history behavior for the transients in the dominant-transient set. Transient 9.43 represents a condition of maximum pressure loading, whereas transient $9.20 \mathrm{~B}$ includes the most severe thermal-hydraulic boundary conditions. In the context of this review the point to note is that the transients span a range of pressure-temperature time-histories sufficiently broad to permit identification of any significant transient-dependant trends in the results. 
Table 1. Six dominant transients account for $75 \%$ of the PTS Risk in the HBR-HYPO Vessel Analysis. The transients are all the result of a stuck-open secondary-side valve following a reactor trip.

\begin{tabular}{|c|c|}
\hline $\begin{array}{c}\text { TRANSIENT SEQUENCE } \\
\text { IDENTIFICATION }\end{array}$ & $\begin{array}{c}\text { THROUGH-WALL CRACK } \\
\text { FREQUENCY (CRACKYEAR) }\end{array}$ \\
\hline 9.41 & $4 \times 10.9$ \\
\hline 9.33 & $3 \times 10^{-9}$ \\
\hline 9.198 & $7 \times 10.10$ \\
\hline 9.94 & $7 \times 10.10$ \\
\hline 9.43 & $5 \times 10.10$ \\
\hline 9.208 & $4 \times 10.10$ \\
\hline
\end{tabular}
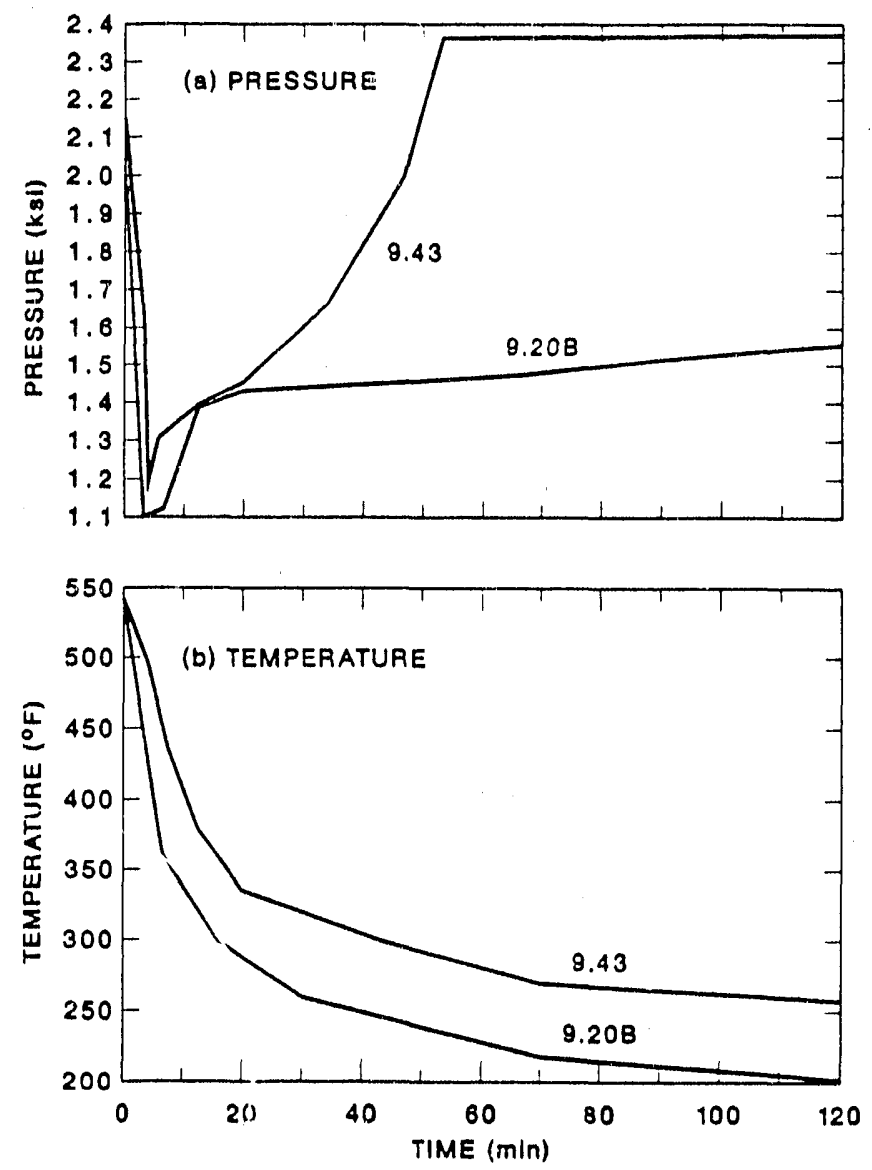

Fig. 1. Transients considered in the PTS analysis of the HBR-HYPO Vessel covered a broad range of downcomer pressure-temperature time-history combinations. 
A majority of the crack initiations predicted in the HBR-HYPO vessel analysis occurred for flaws in the first $2.5 \mathrm{~cm}(1 \mathrm{in}$.) of the vessel wall. A flaw depth of $1.19 \mathrm{~cm}(0.47 \mathrm{in}$.) $(\mathrm{a} / \mathrm{w}=0.05)$ was selected for this review as representative of conditions within the critical section of the wall. Crack-tip stress-intensity factor $\left(\mathrm{K}_{\mathrm{I}}\right)$ time-histories for the selected surface flaw are given in Fig. 2.

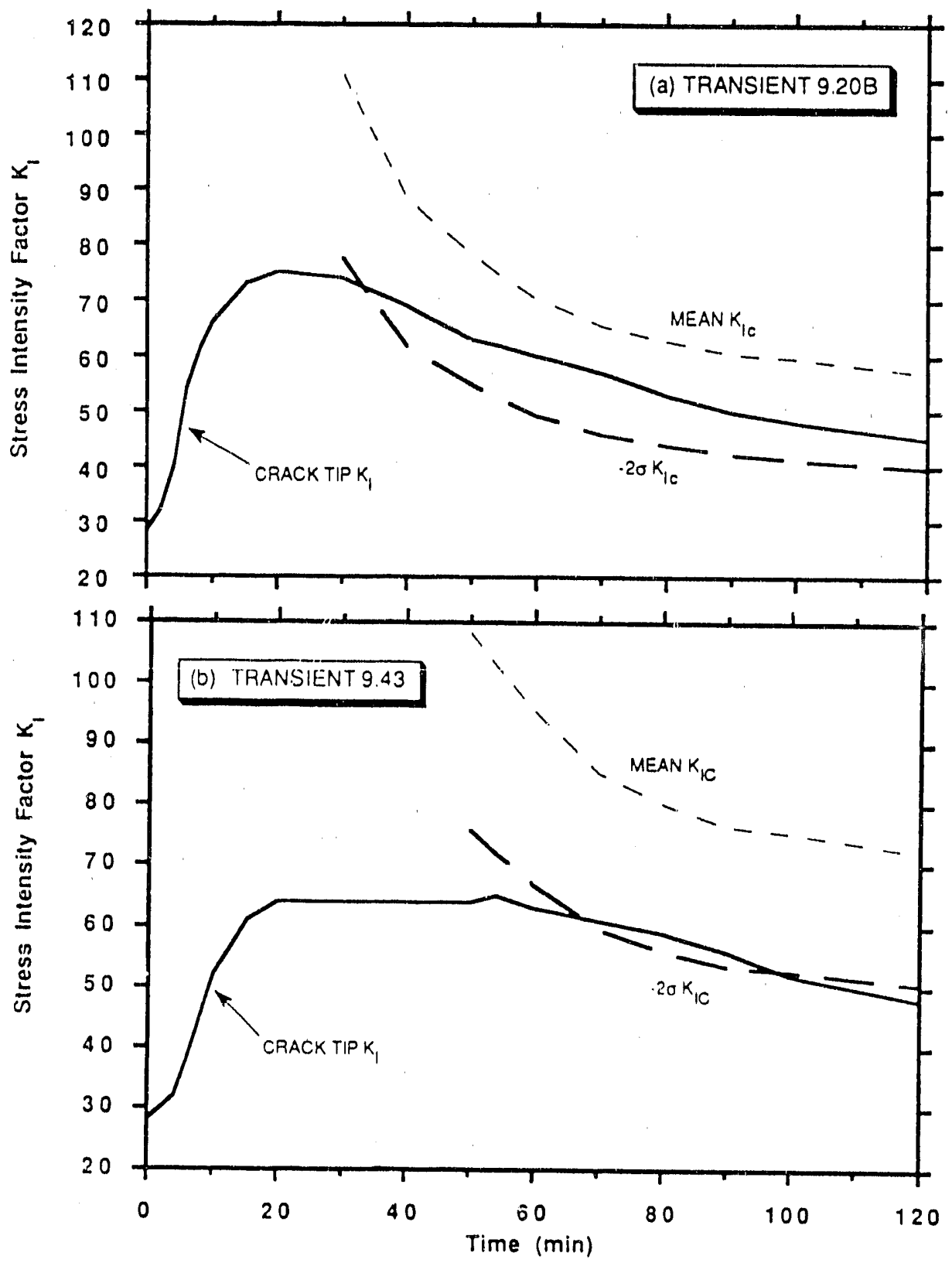

Fig. 2. With the material RTNDT set at a maximum $(+2 \sigma)$ value of $270^{\circ} \mathrm{F}$, the overlap of the $-2 \sigma \mathrm{K} I c$ curve with the applied $\mathrm{K}_{I}$ curve remains in a region where $\mathrm{K}_{I}$ is negative. The warm-prestressing effects associated with these conditions were conservatively neglected in the initial analysis of the HBR-HYPO vessel. 
for each of the bounding PTS transients. The curves of Fig 2 show the crack-tip stress-intensity factor to peak at about 20 minutes into the transients. Thereafter $\mathrm{K}_{I}$ decreases steadily in the case of Transient $9.20 \mathrm{~B}$. This is due to the decrease in thermal stress, as the vessel wall-temperature gradients collapse, exceeding the increase in stress generated by the increasing vessel internal pressure. In the case of transient 9.43 the rates of change of pressure and thermal stress are approximately equal and opposite for a 35-minute period, after which the net stress-intensity factor decreases steadily with time.

Superimposed on the crack tip $K_{I}$ time-histories in Fig. 2 are the mean and $-2 \sigma$ critical-crack stress-intensity-factor $\left(\mathrm{K}_{\mathrm{Ic}}\right)$ curves. These curves were generated assuming a value of $270^{\circ} \mathrm{F}$ for RTNDT and therefore represent an extreme condition of $\mathrm{K}_{\mathrm{Ic}}$ overlap of the applied $\mathrm{K}_{\mathrm{I}}$ curve. Even so, the area of overlap is confined to the portion of the $\mathrm{K}_{I}$ curve where $\mathrm{K}_{\mathrm{I}}$ is changing very gradually with time. Under these conditions, the stress distribution in the vessel wall would approach a smooth curve with a minor perturbation adjacent to the inner surface due to the higher thermal expansion coefficient for the stainless steel cladding. The inference drawn from the data of Fig. 2 is that there is nothing in the characteristics of the applied-transient loading which would cause the distribution of crack initiations through the vessel wall thickness to depart markedly from a smooth curve.

It is evident from the curves of Fig. 2 that the overlap of the KIc curves with the applied KI curves occurs in a region where the slope of the $\mathrm{K}_{\mathrm{I}}$ curve is negative. It has been shown that crack initiation will not occur when $\dot{K}_{I}<0$ (the warm-prestressing effect). 'This condition is recognized in the H. B. Robinson PTS-evaluation report, and is evaluated in a sensitivity analysis performed after first completing the PTS analysis, neglecting the effects of warm prestressing. The net effect of the warm-prestressing sensitivity analysis was to reduce the predicted frequency of throughwall-cracking for the dominant transients by factors which vary from a low of $1 / 5$ to a high of $1 / 300$.

The distribution of fast-neutron fluence through the vessel wall and the resulting local shift in RTNDT is governed by the following equation (Ref. 7 and 8 )

$$
\mathrm{F}=\mathrm{F}_{\mathrm{O}} e^{-0.24 a}
$$

where

$$
\begin{aligned}
& F=\text { fast fluence at depth a in. }\left(\mathrm{n} / \mathrm{cm}^{2}: \text { E.> } 1 \mathrm{MeV}\right) \\
& a=\text { crack depth }(\text { in. }) \\
& F_{O}=\text { fast fluence at the vessel inner surface }\left(\mathrm{n} / \mathrm{cm}^{2}: \text { E.> } 1 \mathrm{MeV}\right) \\
& \Delta R T \text { NDT }=[-10+470 \mathrm{Cu}+350 \mathrm{Cu} \mathrm{Ni}]\left(\mathrm{F} \times 10^{-19}\right) 0.27
\end{aligned}
$$

Where

$$
\mathrm{Cu}, \mathrm{Ni}=\text { concentrations of copper and nickel, wt\%. }
$$

Combining equations (1) and (2) the variation of RTNDT through the vessel wall is seen to be proportional to $\mathrm{e}^{-.0648 \mathrm{a}}$. The values of RTNDT at a depths of $2.54 \mathrm{~cm}$ and $7.62 \mathrm{~cm}$ (1 and 3 in.) beneath the vessel inner surface would thus be $94 \%$ and $82 \%$ of the inner-surface value, 
respectively. This gradual variation of RTNDT through the thickness of the vessel wall would be expected to influence the distribution of crack initiations in a like manner.

The cumulative distribution of crack initiations for each of the dominant transients in Table 1 is shown plotted as a function of the depth of the surface crack in Fig. 3. The curves of Fig. 3(a)
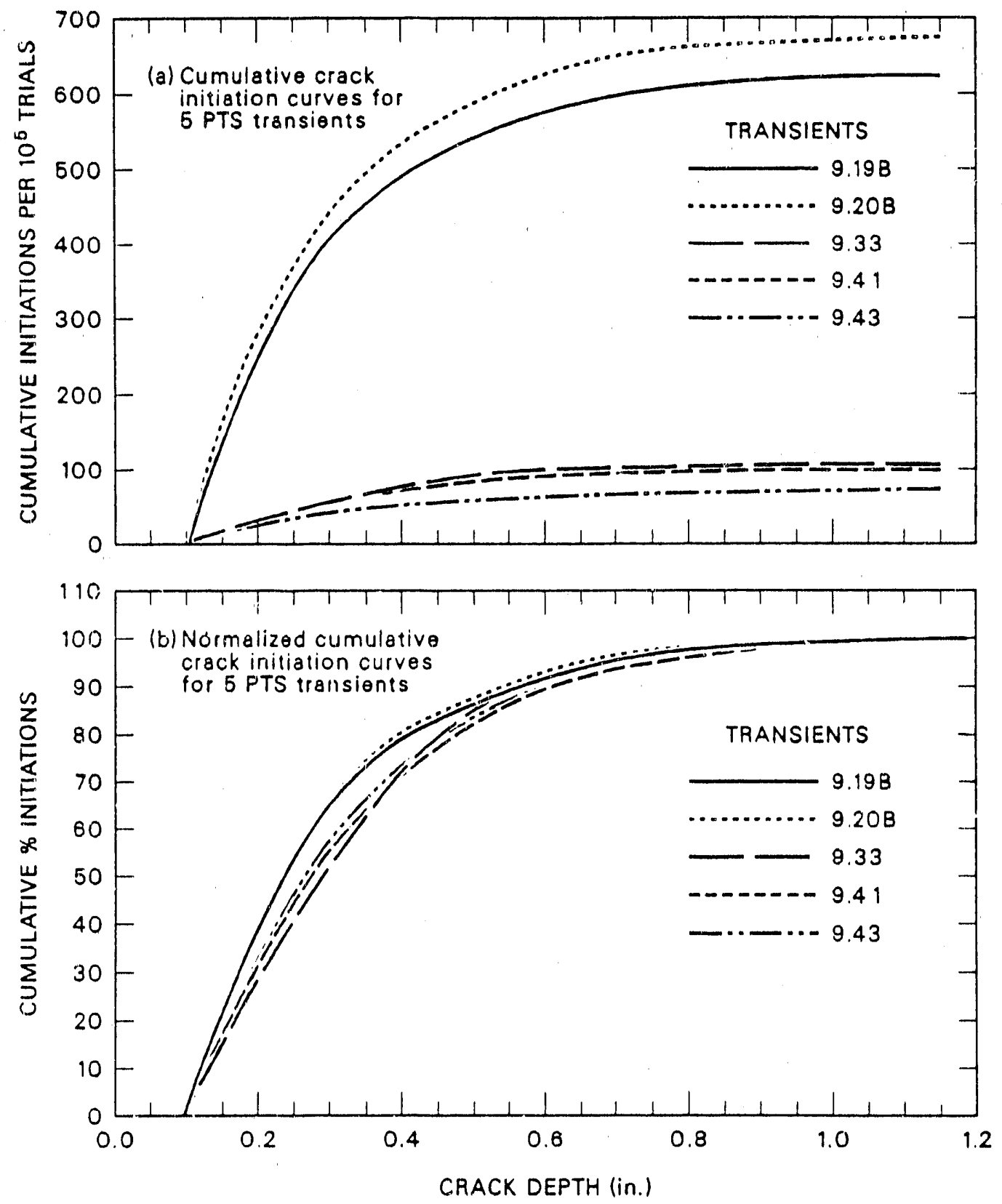

Fig. 3. Cumulative crack-initiation curves from an OCA-P analysis of five different transients are remarkably similar. This suggests the shape of the cumulative crackinitiation curve is dictated by the assumed flaw distribution with analysis input parameters for specific transients having a second-order effect. 
show that the majority of all cracks that initiate originate from flaws located in the inner $2.5 \mathrm{~cm}$ (1 in.) of the vessel wall. The normalized, cumulative crack-initiation curves of Fig. 3(b) show furthermore that the cumulative crack-initiation curves for each of the six dominant transients are remarkably similar.

The remaining parameter which can influence the through-thickness distribution of crack initiations is the input flaw distribution. The similarity of the normalized, cumulative crack-initiation curves for widely differing dominant transients points to the input flaw distribution as the dominant influence on the distribution of crack initiations.

Conclusions drawn from this brief review of the HBR-HYPO reactor vessel PTS analysis are:

(a) The major portion of the predicted crack initiations originate at flaws located in the inner $2.5 \mathrm{~cm}$ ( 1 in.) of the reactor vessel wall.

(b) Factors which influence the fracture toughness of material within the inner $2.5 \mathrm{~cm}$ ( $1 \mathrm{in}$.). of the vessel wall can have a significant impact on the outcome of a reactor vessel probabilistic PTS analysis. Factors in this category include cladding effects, restraint release due to the proximity of a free surface (shallow flaws), metallurgical gradients and possibly conditioning of the material by subcritical cyclic straining.

(c) The input flaw density and distribution functions have a dominant influence on the number and distribution of predicted crack initiations.

\section{Flaw Density and Distribution}

The reactor vessel flaw population is at the same time both the most influential and the most ill defined of the input parameters to a PTS analysis. The problem stems from an absence of relevant data. Nondestructive volumetric-examination techniques in use at the time most of the reactor vessels currently in service were constructed lacked the detection and resolution capability to accurately characterize the population of small, sharp-edged flaws. These are the flaws of primary concern in a PTS analysis. The problem is compounded by the fact that the flaws of primary concern are those located close to the inner surface of the reactor vessel. In this region the detection and sizing capability of NDE systems is further degraded by the proximity of the stainless steel reactor vessel cladding.

Flaw density and distribution estimates used in the PTS analysis of Ref. 7 were taken from a study performed by the United Kingdom Atomic Energy Authority under the chairmanship of Dr. W. Marshall (Refs. 9 \& 10). The Marshall report flaw data were taken from ultrasonic inspections of 44 LWR vessels made "essentially to ASME III rules". Ultrasonic inspections were made at approximately the time the vessels entered service. The flaw population discovered in these inspections can therefore be considered relevant to the population of LWR vessels as delivered to nuclear plants.

Twelve defects were found in the inspection of 44 vessels. The defects were all in the size range $1.25 \mathrm{~cm}(0.5 \mathrm{in}$.) $<\mathrm{a}<2.5 \mathrm{~cm}(1.0 \mathrm{in}$.). No defects were found with a size in excess of $2.5 \mathrm{~cm}$ (1.0 in.). Data from a non-nuclear vessel (Ref. 11), which failed during its hydro test due to the presence of a large flaw, were used to supplement the nuclear vessel data base. 
The absence of data on defects in the size range a $<1.25 \mathrm{~cm}(0.5 \mathrm{in}$.) was not considered to be a concern in the evaluatiors of Ref. 9. The basis for this position was an assessment that defects in the size range a $<1.25 \mathrm{~cm}(0.5$ in.) would not grow to a significant size provided the vessel material toughness remained on the upper shelf. Results from the HBR-HYPO vessel PTS analysis however indicate that a major portion of the crack initiations occurred at defects in this size range. It is important to recognize therefore that the significance of shallow flaws incorporated into the Marshall report assessment of flaw densities differs from that inferred from the HBR-HYPO PTS analysis. It is also important to recognize that the absence of data on flaws in the size range a $<1.25 \mathrm{~cm}(0.5 \mathrm{in}$.$) is probably a reflection of the detection and sizing capabilities of the ultrasonic$ equipment and procedures used in the inspection rather than an indication of the absence of flaws in this size range.

Inspection results were used to derive functions which define the probability of having a flaw in the reactor vessel welds in a size (through-thickness dimension) range $\Delta a$. The probability was expressed in terms of a flaw density, a flaw-size distribution function and a detection-probability function. The latter function represents the probability of detecting the flaw during a preserviceultrasonic inspection. As used in the PTS analysis of Ref. 7, the flaw density, distribution and detection-probability functions have the following form.

$$
\begin{aligned}
& P\left(\Delta \mathrm{a}_{\mathrm{i}}\right)=N V \int_{\Delta \mathrm{ai} .} f(\mathrm{a}) \mathrm{B}(\mathrm{a}) \mathrm{da} \\
& f(\mathrm{a})=4.1 e^{-4.1 \mathrm{a}} \\
& B(\mathrm{a})=0.005+0.995 e^{-2.87 a}
\end{aligned}
$$

Where

$$
\begin{aligned}
& P\left(\Delta a_{1}\right)=\quad \text { The probability of having a flaw in a specific region within the depth } \\
& \text { range } \Delta \mathrm{a}_{\mathrm{i}} \\
& f(a)=\text { flaw-depth-density function } \\
& \mathrm{B}(\mathrm{a})=\text { probability of nondetection in a preservice or in-service ultrasonic. } \\
& \text { inspection. } \\
& \mathrm{N}=\text { number of flaws of all depths per unit volume } \\
& \mathrm{V}=\quad \text { volume of the specific region } \\
& \text { a }=\text { crack depth, in.,(the analysis of Ref. } 7 \text { used English units) }
\end{aligned}
$$

and

$$
\int_{0}^{\infty} \cdot f(a) d a=1
$$


Generation of the flaw-population definition embodied in Eqs. 3, 4 and 5 represents a considerable achievement. Consideration of modified-flaw population representations is possible at this time because of (a) insights obtained from the PTS analysis of the HBR-HYPO reactor vessel into the effect of flaw density and distribution assumptions on the analysis results and (b) additional flaw density and distribution data obtained from the non destructive and destructive examination of welds cut from surplus reactor vessels.

Equations 3, 4 and 5 provide a definition of the number and size distribution of flaws located within a given volume of weld metal, but they provide no information on the spatial distribution of the flaws within the thickness of the vessel wall. The data base from which the flaw population density and distribution functions were generated was comprised of flaws discovered using ultrasonic inspection. Given the ultrasonic inspection technology and practices in use at the time these data were collected it is reasonable to assume that the flaws in the data base were located in the body of the weld. It was common practice at that time to exclude the surface volume of the weld from the ultrasonic inspection gate to avoid the problems of spurious signals caused by the inner surface stainless steel cladding. It is considered unlikely therefore that the flaws included in the data base were located in the region of the weld adjacent to the inner surface of the reactor vessel.

The analysis of Ref. 7 considered all flaws to be surface flaws. This approach assured a conservative result from the analysis since, given identical boundary conditions, $\mathrm{K}_{\mathrm{I}}$ for a surface

flaw is greater than that for a buried flaw of the same radial depth by a factor of $\sqrt{2}$. The surface flaw assumption had the additional effect of imposing a spatial distribution on the flaws which did not derive from the data base.

The imposed spatial distribution of flaws deriving from the surface-flaw assumption placed the major portion of the flaw population in a region of the vessel wall where both irradiationembrittlement effects and transient thermal stresses are at a maximum. Figure 3(b), which shows the normalized, cumulative crack-initiation curves to be very similar for a broad range of PTS transients, suggests that the imposed spatial distribution of the flaw population has a dominant effect on the analysis results.

Close coupling between the input spatial flaw distribution and the output crack initiation distribution is further illustrated in Fig. 4(a). The mean cumulative crack initiation curve for the five dominant transients is seen to have characteristics similar to those of the cumulative flawdistribution curve. Application of a relatively simple correlation function to the input cumulative flaw distribution can produce a close fit to the normalized cumulative crack-initiation curves for a broad range of PTS transients. An estimated normalized, cumulative crack-initiation curve produced in this manner is shown in Fig. 4(b). It is evident from Fig. 4(b) that the assumed spatial distribution of the input flaw population has a dominant influence on the normalized cumulative crack-initiation output curve from a PTS analysis.

Thermal-stresses and irradiation-damage levels are highest in material adjacent to the inner surface of the vessel. By placing the majority of the flaws in this region, the assumed spatial distribution of vessel flaws influences both the distribution and frequency of crack initiations. The influence on crack-initiation frequency is in addition to that associated with the conservative crack depth used in calculation of crack-tip stress-intensity factors. Interest in the influence of the assumed spatial distribution of vessel flaws derives primarily from its effect on crack-initiation frequency.

At this point it would be possible to conclude that the imposition of a spatial distribution on the flaw population which did not derive from the flaw data base had introduced an element of 

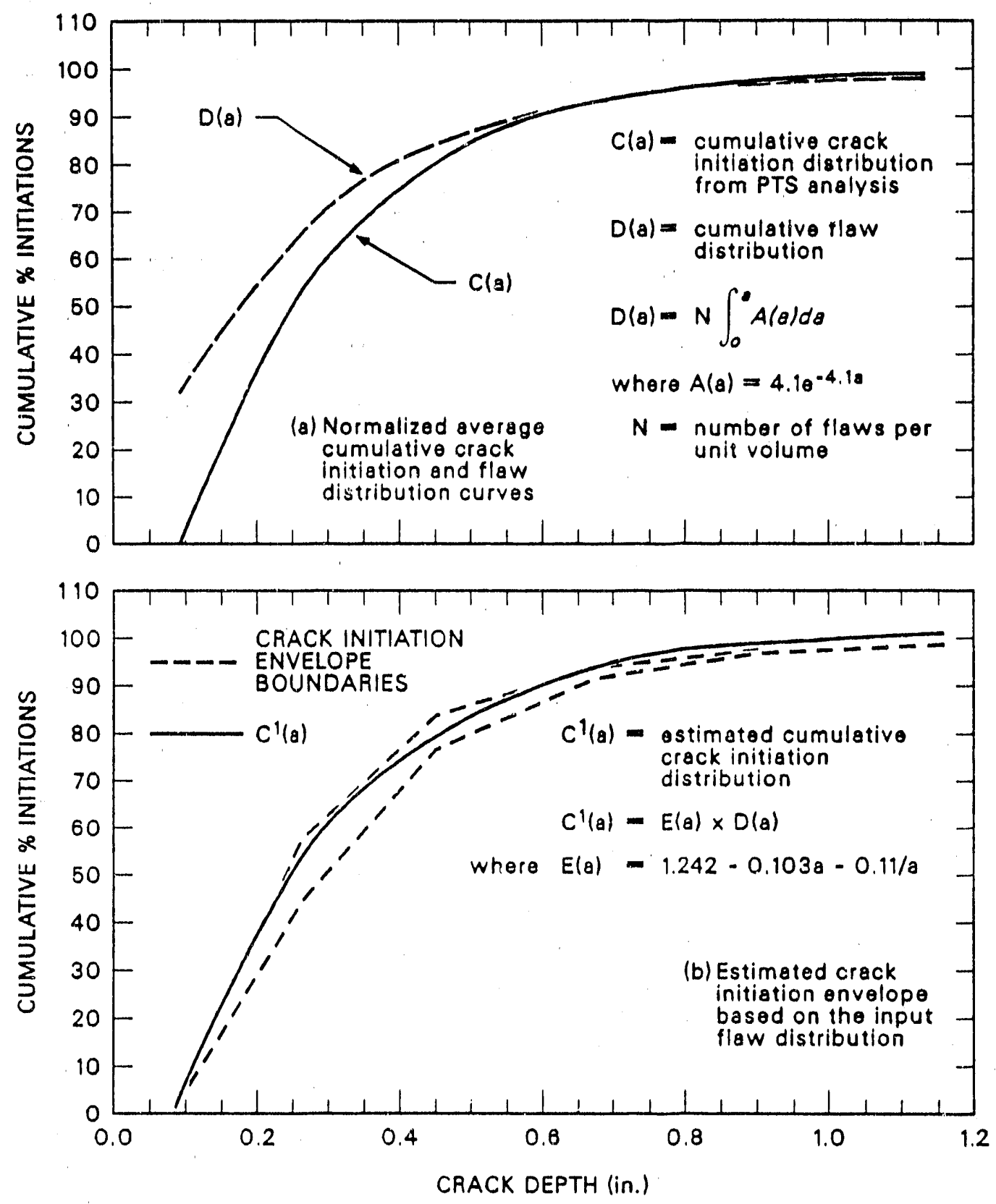

Fig. 4 The normalized average cumulative crack-initiation curve for five PTS transients is similar to the cumulative flaw-distribution curve. An estimated cumulative crackinitiation curve for the NUREG/CR-4183 analysis can be generated by factoring the input-flaw distribution by a linear-hyperbolic correlation parameter.

conservatism into the analysis. A review of the impact of subsequent additions to the flaw data base however leads to an opposite conclusion.

Weld material cut from the surplus Hope Creek BWR vessel was recently inspected by ORNL (Ref. 12). One flaw was found in the inspection of $0.03 \mathrm{~m}^{3}$ of weld metal. Non-destructive 
examination of material from the surplus Midland PWR vessel is currently in progress at the EPRI NDE Center at Charlotte, NC (Ref. 13). To date this examination has revealed two to three subclad indications in an examination of $8.2 \mathrm{~m}$ (27 ft.) of weld material. Note that all of the indications/flaws found are located within $2.5 \mathrm{~cm}$ (1 in.) of the vessel inner-wall surface.

It is evident from the prior discussion that the flaw population exerting the dominant influence on crack initiation is that located within $2.5 \mathrm{~cm}(1 \mathrm{in})$ of the vessel wall inner surface. The vessel weld examinations described above have provided data on both the density and spatial distribution of flaws. To evaluate the significance of these data, it is therefore convenient to express all of the flaw densities in terms of that volume of weld metal located within $2.5 \mathrm{~cm}$ (1 in) of the vessel inner surface.

The flaw density used in the PTS analysis of Ref. 7 was $1 \mathrm{flaw} / \mathrm{m}^{3}$. Integration of the flaw-depth density function of Equation 4 between the limits of $a=0$ to 1 in $(2.5 \mathrm{~cm})$ gives a value in excess of $98 \%$ for the subset of the total flaw population located in this region of the vessel wall. The wall thickness of the HBR-HYPO reactor vessel was $23.88 \mathrm{~cm}(9.4 \mathrm{in})$. In terms of the flaw density in the critical inner $2.5 \mathrm{~cm}$ ( $1 \mathrm{in}$.) of the vessel wall therefore the flaw density used in the analysis translates into a "surface density" Ns of

$$
\text { Ns }=1 \times 0.98 \times 23.88 / 2.5=9 \text { flaws } / \mathrm{m}^{3}
$$

The Hope Creek vessel plate was $17.1 \mathrm{~cm}(6.73$ in) thick. The surface-flaw density for this material is therefore

$$
\mathrm{Ns}=(1 / 0.03) \times(17.1 / 2.5)=228 \text { flaws } / \mathrm{m}^{3}
$$

In the case of the Midland reactor vessel material it is important to recognize that characterization of the indications has not yet been completed. If however the 3 subclad indications are confirmed as flaws and the weld width within the surface volume is taken as $5 \mathrm{~cm}(2 \mathrm{in})$, the surface-flaw density is obtained as

$$
\mathrm{Ns}=3 /(0.025 \times 0.05 \times 8.2)=293 \mathrm{flaws} / \mathrm{m}^{3}
$$

The recent reactor vessel weld flaw-population data, while admittedly sparse, indicate that the flaw density used in the PTS analysis of Ref. 7 may have been low by a factor in excess of one order of magnitude.

The final factor to be considered in the evaluation of the input flaw density and distribution functions is the "nondetection probability" factor B(a), as defined in Equation 5. The probability of detection-factor curve [1-B(a)] is shown in Fig. 5 superimposed on envelope plots of (a) the detection capability of ultrasonic testing technology as determined in the PISC II round-robin UT trials (Ref. 14) and (b) the crack-initiation profiles for the dominant transients from the PTS analysis of Ref. 7.

It is evident from the plots of Fig 5 that the flaw-detection capability estimates used to derive Equation 5 were optimistic. Equation 5 predicts a flaw detection rate in excess of that achieved by the highest performing team in the PISC trials for a major portion of the flaw-size range of interest in a PTS analysis. It should be noted that the PISC II results show better detection performance for volumetric flaws. The results of interest relative to the PTS analysis are those for the sharpedged cracks however, and the detection rates for those cracks were as indicated in Fig. 5. 


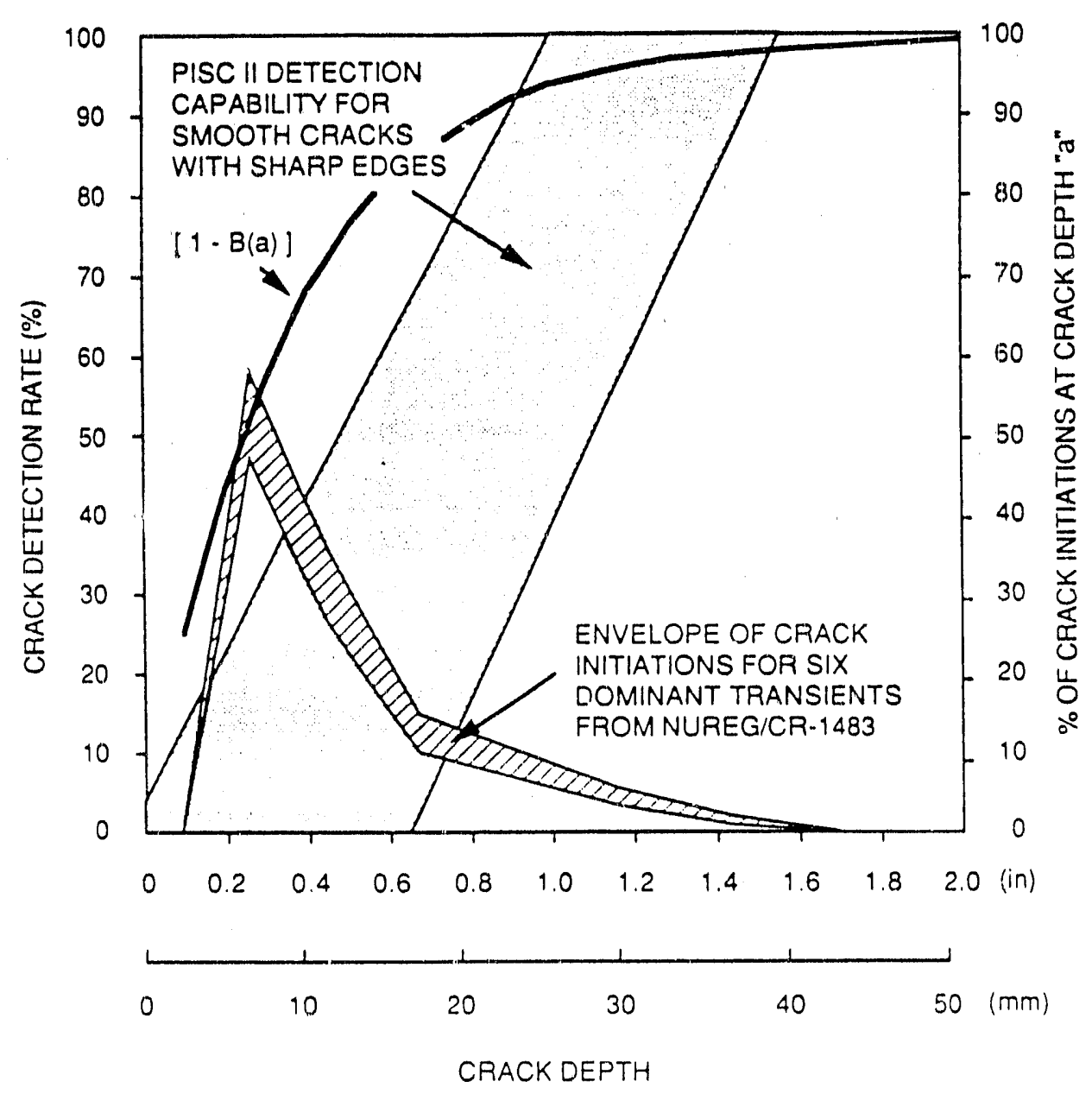

Fig. 5 PISC II NDE results obtained using ASME procedures with 20\% DAC indicate a low probability of detecting the smooth sharp-edged cracks of concern ir. "DTS analysis.

The PISC II results show that inspection teams performing at the lower hound of the performance envelope would have a very low detection rate for the flaws of interest in a PTS analysis. These results indicate it would be prudent to consider elimination of the flaw-detection element from the PTS analysis until such time as the performance of ultrasonic NDT systems is substantially improved.

\section{Shallow Flaws}

Shallow-flaw fracture-toughness tests have been performed at the University of Kansas (U of Kan.) under the direction of Dr. S. T. Rolfe (Refs. 15 and 16). Materials investigated in the U. of Kan. program to date include A36 $\left(\sigma_{y}=36 \mathrm{ksi}\right)$ and A517 $\left(\sigma_{\mathrm{y}}=100 \mathrm{ksi}\right)$. Yield strengths for these materials bracket that of A533B ( $\left.\sigma_{y}=68 \mathrm{ksi}\right)$, used in the construction of many PWR and BWR pressure vessels. It is anticipated therefore that A533B will exhibit the enhanced shallowflaw fracture toughness demonstrated in the U. of Kansas A36 and A517 programs. 
Shallow-flaw fracture-toughness curves from the U. of Kansas A36 and A517 programs are reproduced in Figs. $6(\mathrm{a})$ and $6(\mathrm{~b})$, respectively. The shallow-flaw fracture-toughness-elevation effect is seen to increase from zero on the lower shelf to a maximum in the lower-transition region of the curves. PTS analysis shows that crack initiatons within the inner $2.5 \mathrm{~cm}(1.0 \mathrm{in}$.) of the reactor vessel wall typically occur at crack-tip temperatures corresponding with lower transitionzone temperatures for irradiated reactor vessel material. It is to be anticipated therefore that elevated shallow-flaw fracture-toughness properties could have a significant influence on results from a PTS analysis.

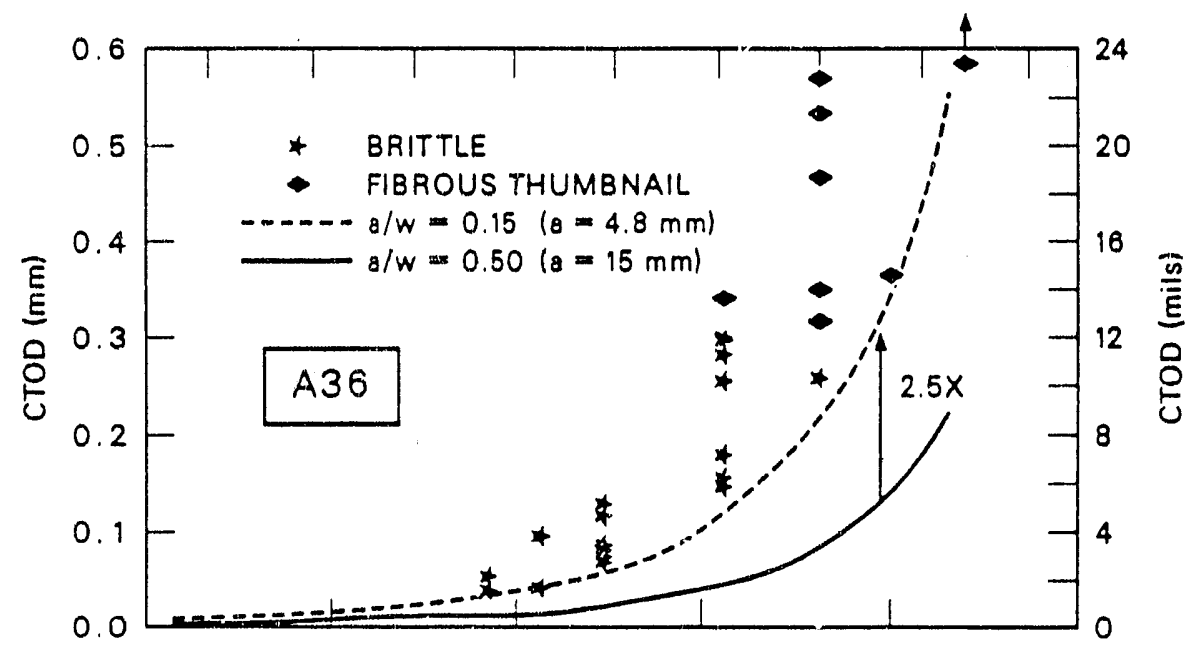

TEMPERATURE $\left({ }^{\circ} \mathrm{F}\right)$

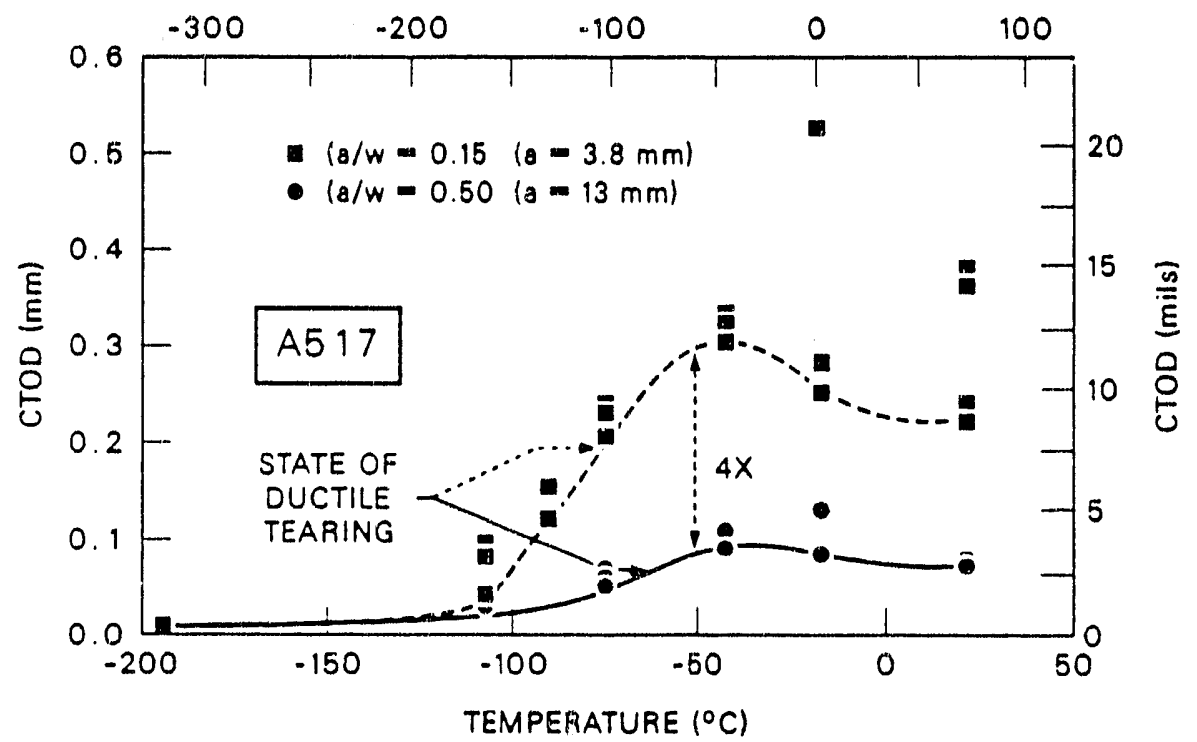

Fig. 6. Shallow-flaw fracture toughness tests performed at the University of Kansas have shown elevated fracture toughness in $A 36\left(\sigma_{y}=36 \mathrm{ksi}\right)$ and $\mathrm{A} 517\left(\sigma_{\mathrm{y}}=100 \mathrm{ksi}\right)$. Similar shallow-flaw behavior is anticipated in A533B $\left(\sigma_{\mathrm{y}}=68 \mathrm{ksi}\right)$. 
A sensitivity analysis was performed to determine the potential impact of an A533B sha"low-flaw fracture-toughness data base on the outcome of a reactor vessel PTS analysis. This analysis was performed as a part of tile screening process to determine the utility of adding a shallow-flaw fracture-toughness-testing task to the HSST Program.

Shallow-flaw fracture-toughness curves for A533B were estimated by interpolating between the shallow-flaw curves for A36 and A517 given in Fig 6. The procedure used first estimated A533B curves for $a / w$ ratios of 0.15 and 0.5 using the material -yield stress as the interpolation parameter. In the case of the $A 36$ test specimens, a/w ratios of 0.15 and 0.5 corresponded to absolute flaw depths of $4.8 \mathrm{~mm}(0.19 \mathrm{in.})$ and $16 \mathrm{~mm}$ (0.63 in.), respectively.

The relative influence of the flaw-depth ratio $(a / w)$ and the absolute flaw depth (a) on shallow-flaw behavior remains an open issue at this time. In the following evaluation the absolute flaw depth (a) was used as the controlling parameter. This approach should produce a conservative estimate of the potential benefits of enhanced shallow-flaw fracture toughness since the effects were assumed not to exist beyond the maximum flaw depth of $16 \mathrm{~mm}$ tested in the U. of Kan. program.

Shallow flaw fracture-toughness enhancement was assumed to vary in a manner producing the maximum enhancernent at a flaw depth of $4.8 \mathrm{~mm}(0.19 \mathrm{in}$.) and zero enhancement at a flaw depth of $16 \mathrm{~mm}(0.63 \mathrm{in}$.). Variation of shallow flaw fracture toughness enhancement between these two bounding crack-depth values was assumed to be controlled by a modified-sine curve. Results from this estimation procedure were expressed in terms of factors giving the increase in fracture toughness for a given crack depti relative to an assumed lower-bound $(-2 \sigma)$ value at a crack depth of $16 \mathrm{~mm}(0.63 \mathrm{in}$.) These factors were then applied to the ASME Section XI KIc curve to produce estimated $-2 \sigma$ shallow flaw $\mathrm{K}_{\mathrm{Ic}}$ curves for use in an exploratory PTS analysis.

Analysis of the HBR-HYPO vessel response to the 9.22B PTS transient was used to evaluate the effect of enhanced fracture toughness for shallow flaws. Crack-initiation data from the original analysis reported in Ref. 7 are shown in Fig. 7 (a), together with the associated critical crackdepth curves in Fig. 7(b). The area under the crack-initiation curve for the original analysis of Ref. 7 provides the baseline for assessing the potential effect of shallow-flaw fracture-toughness enhancement.

Results from an OCA-P analysis of the response of the HBR-HYPO vessel with enhanced shallow-flaw fracture toughness are shown superimposed on the critical crack-depth curves of Fig. 7(b). The intercept of this curve with the warm-prestressing line defines the minimum depth for crack initiation with enhanced shallow-flaw fracture-toughness properties. Projection of this intercept to the crack-initiation plot show's that approximately $2 / 3$ of the previously predicted crack initiations would be eliminated by the enhanced shallow-flaw fracture toughness. Given the conservative nature of this scoping evaluation, the result obtained provides justification for an experimental investigation of shallow-flaw fracture-toughness enhancement in reactor pressure vessel steels.

Preparations for shallow-flaw fracture-toughness testing of A533B specimens within the HSST program are well advanced. The specimen selected for the initial explotatory tests is a $5.08 \mathrm{~cm}$ ( 2.0 in.) wide and $10.16 \mathrm{~cm}$ (4.0 in.) deep single-edge notched beam. The beam has a span to depth ratio of 4 and is loaded in 3-point bending. Crack depth (a) to beam depth (w) ratios vary from a minimum of 0.05 to a maximum of 0.5 . Figure 8 shows some of the development batch of test specimens, while Fig. 9 shows a beam specimen loaded into the 3-point bend test fixture in an Instron model 1336 servo-hydraulic test machine. 


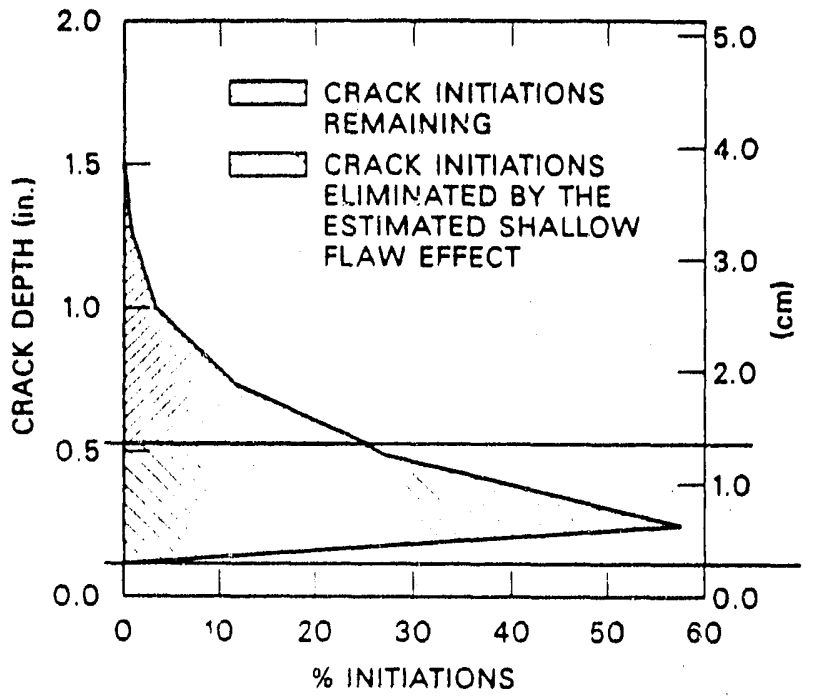

(a) CRACK INITIATION DISTRIBUTION

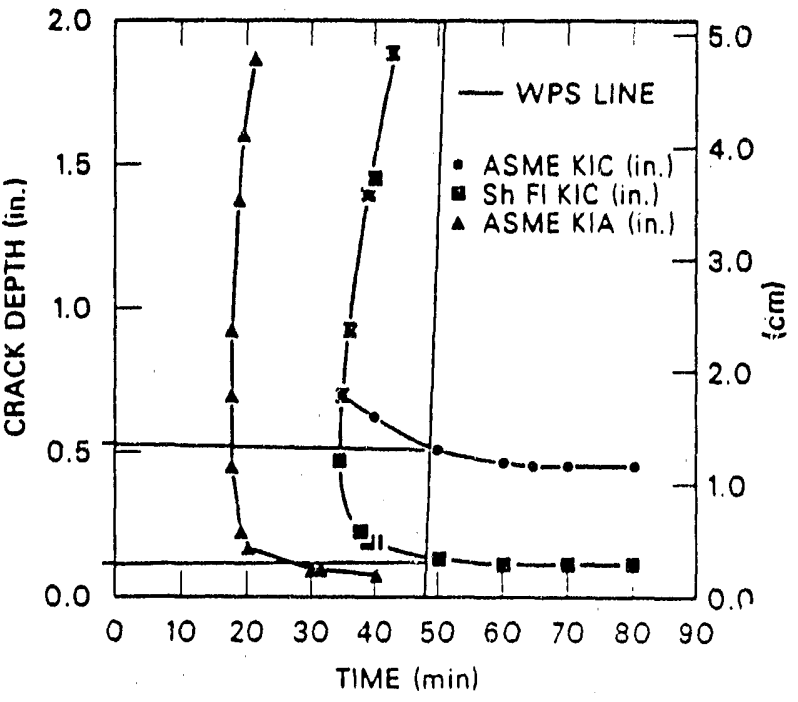

(b) CRITICAL CRACK DEPTH CURVES

Fig. 7. Inclusion of an estimated shallow-flaw fracture-toughness increase in a PTS analysis using the $\mathrm{H}$. B. Robinson $9.22 \mathrm{~B}$ transient results in a significant decrease in the number of predicted crack initiations.

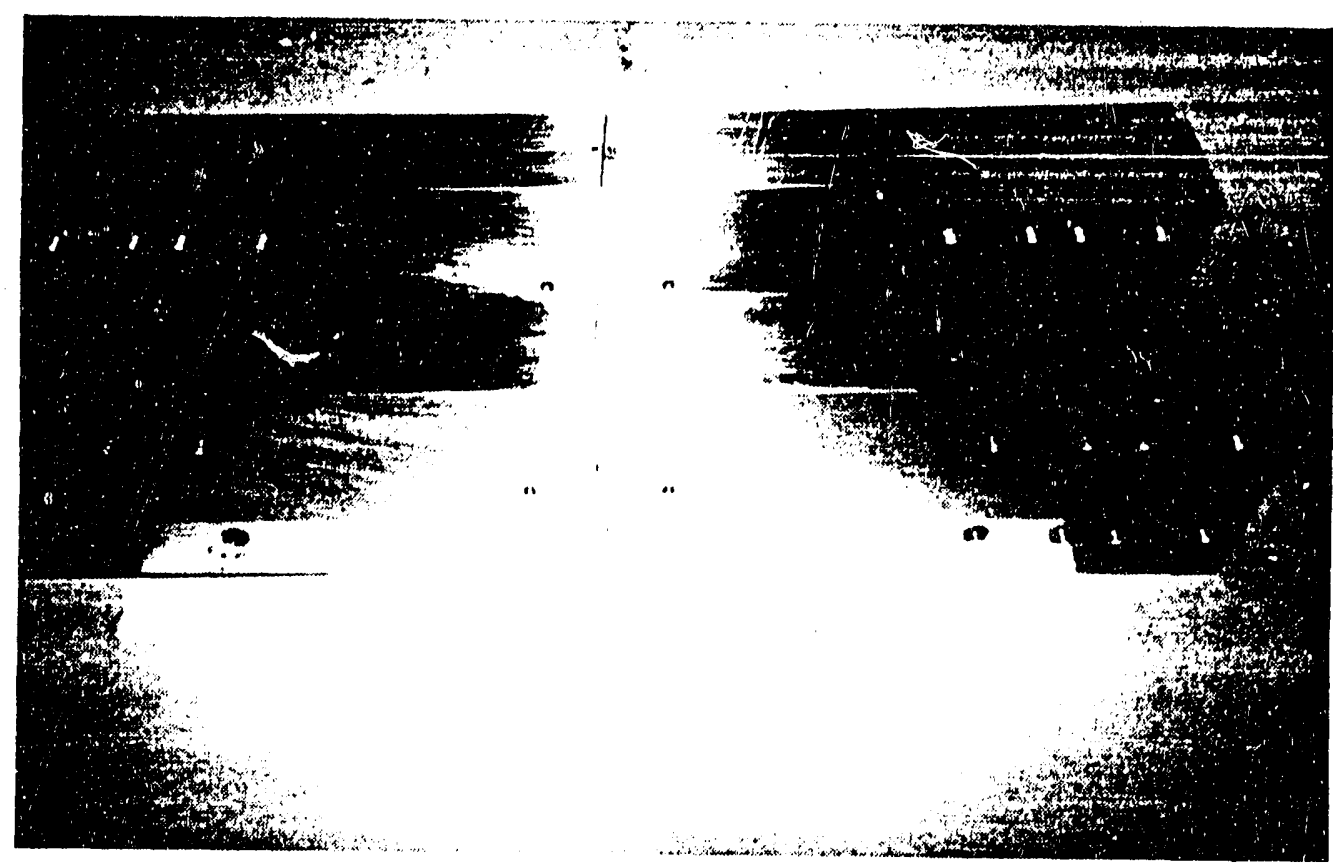

Fig. 8. Test specimens used in the A533B shallow-flaw fracture-toughness testing program are $5.08 \mathrm{~cm}(2 \mathrm{in.})$ wide and $10.16 \mathrm{~cm}(4 . \mathrm{in}$.$) deep. Flaw a/w ratios range from$ 0.05 min. to 0.5 max. 


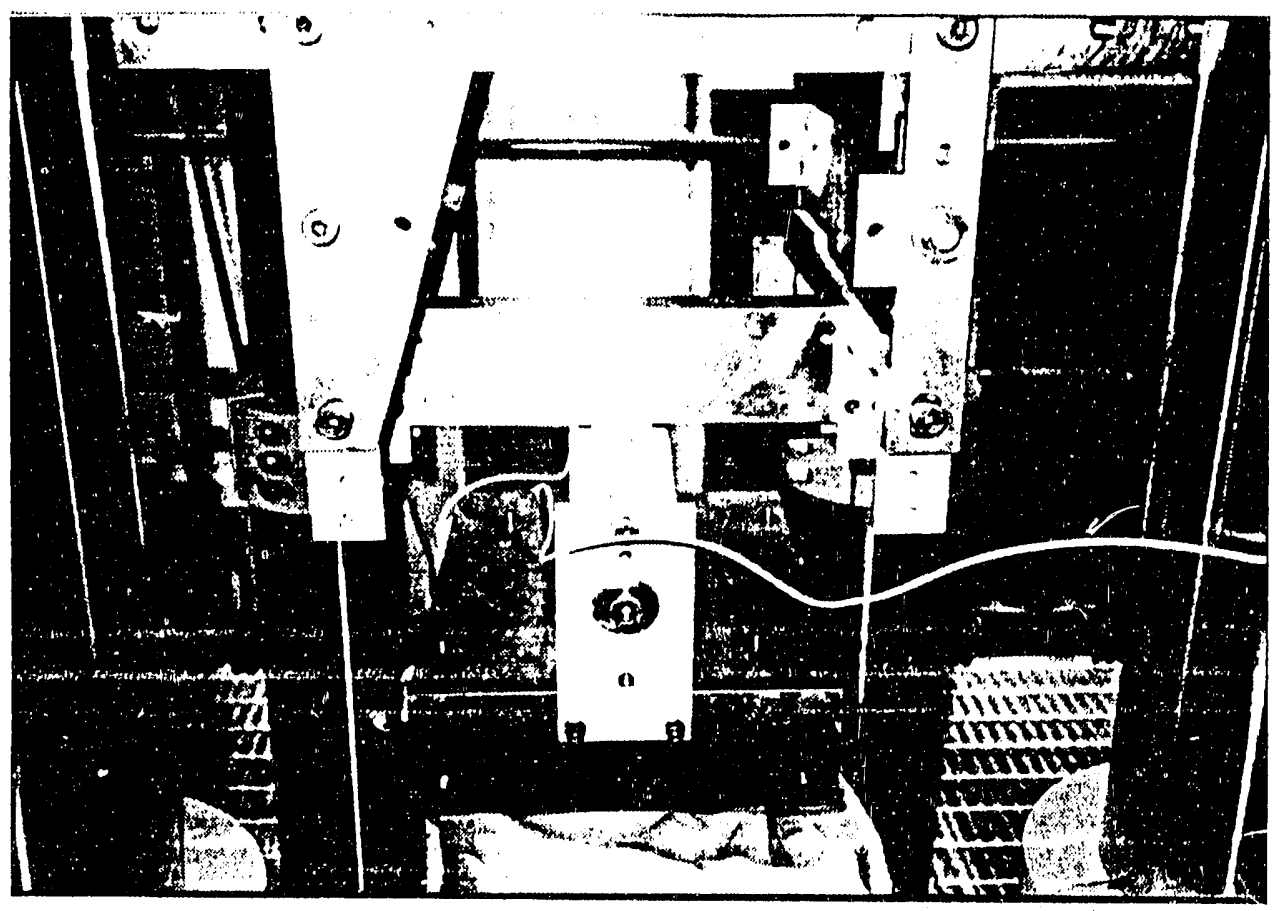

Fig. 9. The shallow-flaw fracture toughness test specimens are loaded in 3-point bending in an Instron model 1336 Servo hydraulic test machine for both fatigue precracking and fracture-toughness testing.

Elastic-plastic finite-element analysis of the test specimens was per Jrmed as a part of the specimen-design process. Results from these analyses are of interest in that they illustrate the growth of the crack -tip yield zone believed responsible for the relaxation of crack-tip constraint in shallow flaws. These results are shown in Fig. 10 in the form of elastic and plastic zones in the specimen at loads estimated to generate crack-tip $\mathrm{K}_{\mathrm{I}}$ values equal to $\mathrm{K}_{\mathrm{c}}$ at the planned test temperature of $-60^{\circ} \mathrm{C}\left(-76^{\circ} \mathrm{F}\right)$. Values of $\mathrm{K}_{\mathrm{C}}$ used in this analysis were estimated using a procedure similar to that described previously. In this case, however, the baseline used to estimate the enhanced shallow flaw fracture toughness was the mean fracture toughness derived from the ASME Section XI KIC -data base. RT NDT for the test materi..l $-35^{\circ} \mathrm{C}(-31 \mathrm{~F})$ was obtained from characterization tests (Ref. 17).

The results of Fig. 10 show clearly the loss of plastic-zone constraint at the onset of fracture for crack depths in the range $0.51 \mathrm{~cm}(0.2 \mathrm{in}.) \leq \mathrm{a} \leq 1.02 \mathrm{~cm}(0.4 \mathrm{in}$.). The cumulative crack-initiation curves of Fig. 3B show this to be a crack-depth range in which a substantial portion of the predicted crack initiations occur. These analysis results reinforce the assessment that enhanced shallow-flaw fracture toughness may have a significant impact on the PTS analysis of reactor pressure vessels. 


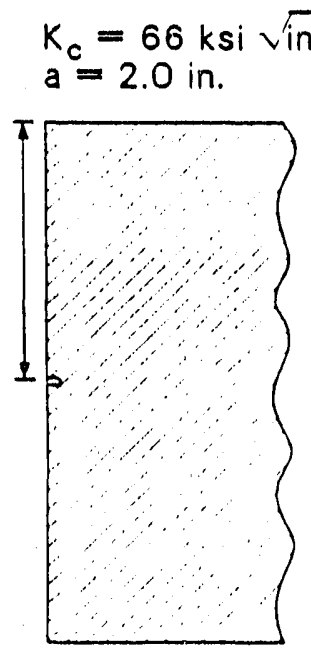

$a / w=0.5$

$$
\begin{aligned}
& k_{c}=73 \mathrm{ksi} \sqrt{\mathrm{in} .} \\
& a=0.6 \mathrm{in} .
\end{aligned}
$$

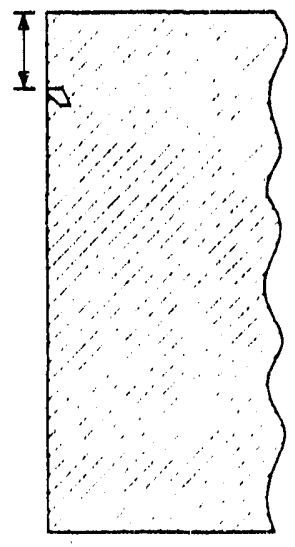

$a / w=0.15$

ELASTIE
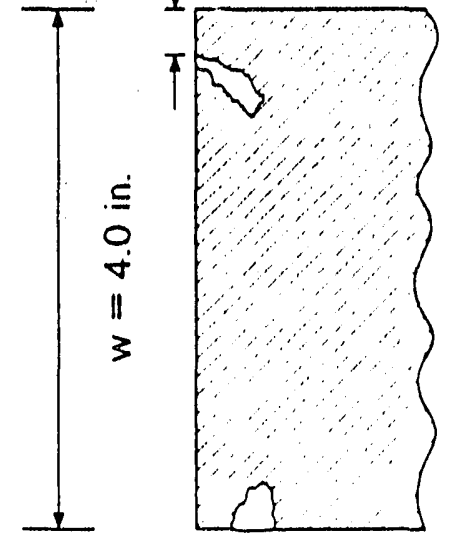

$a / w=0.10$

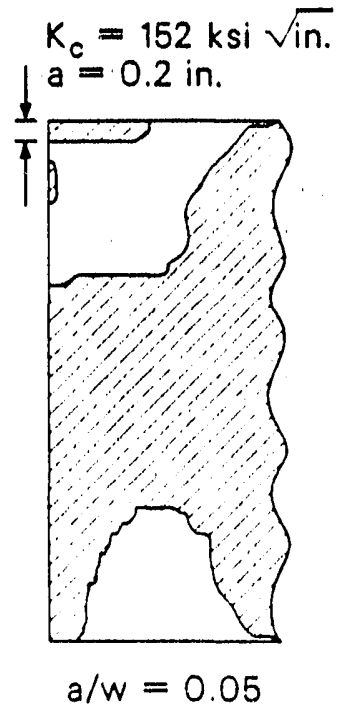

PLASTIC

Fig. 10. Elastic-plastic analysis of the $10.16 \mathrm{~cm}$ (4 in.) deep beam specimens for the shallowflaw testing program clearly shows loss-of-constraint at the crack tip for $a / w$ ratios less than 0.10 . The enhanced fracture toughness observed for shallow flaws is attributed to uncontained crack-tip yielding.

\subsection{Fracture Technology Issues}

A number of generic fracture technology issues have been identified in recent years. The HSST program is currently addressing three such issues which have the potential for significant impact on the analysis of PTS events. The issues of concern here are (a) fracture toughness data transfer, (b) circumferential cracks, and (c) ductile tearing.

\subsection{Fracture Toughness Data Transfer}

Results from the analysis of the HSST program wide-plate crack-arrest specimens provide a convenient illustration of the fracture-toughness data transfer issue (Ref. 18). Materials characterization data obtained from tests using 1T, 2T, and 4T compact-test specimens were used to generate pretest predictions of the wide-plate specimen crack-initiation loads. Loads required to initiate fracture in the wide-plate tests weie substantially higher than had been predicted. $\mathrm{K}_{\mathrm{I}} / \mathrm{K}_{\mathrm{Ic}}$ ratios at crack initiation for the Series 1 wide-plate tests were in the range $1.96 \leq \mathrm{K}_{\mathrm{I}} / \mathrm{K}_{\mathrm{Ic}} \leq 3.97$.

The discrepancy between the predicted and observed crack initiation toughnesses was in a conservative direction in the case of the wide-plate Series 1 test specimens. There is no basis, however, for concluding that this would always be the case. The discrepancy in the predicted fracture behavior of large-scale structures fabricated from well-characterized material raises a basic issue relative to the adequacy of the linear elastic fracture mechanics technology used to generate the pretest fracture predictions. In this connection, it is appropriate to note that a substantial portion of the $\mathrm{K}_{\mathrm{I}} / \mathrm{K}_{\mathrm{Ic}}$ discrepancy remained after corrections had been made for the potential lossof-plane strain constraint at the crack tip using Irwin's $\beta$ factor. 
An ongoing investigation within the HSST program seeks to obtain an improved understanding of relationships governing the transfer of fracture toughness data from small-scale specimens to largescale applications (Ref. 19). Two basic approaches are being investigated. The first approacin is aimed at developing a micro-mechanical model in which fracture is governed by fundamental material properties. Objectives of this approach are to generate a fracture model and supporting materials data which can be applied under conditions when single parameter characterization of the fracture process is no longer valid. This approach is in the early stages of development.

The second approach seeks to develop auxiliary fracture characterization parameters. which can be used, in conjunction with existing correlation based fracture parameters, to improve the accuracy of fracture predictions. Preliminary results from the approach have indicated that auxiliary fracture correlation parameters exist which may be capable of development to meet the task objectives. The parameter showing most promise at this time is one based on the area $\left(A_{C R}\right)$ bounded by a crack tip stress contour corresponding to Hahn's (Ref. 20) estimate of the cleavage-crack propagation stress for ferrite grains.

Fine-mesh, elastic-plastic finite-element analysis of the wide-plate Series 1 test specimens and the asscciated compact test characterization specimens is the technique used to search for auxiliary fracture-correlation parameters. Data for the specimens (structures) considered in this study are given in Fig. 11. The specimens can be seen to differ considerably in both geometry and size.

Finite-element models used in the study are illustrated in Fig. 12. Elastic-plastic analyses of these 2-D and 3-D models were performed using using the ADINA computer program (Ref. 21). Results obtained from the analyses are shown in Fig. 13 in the form of the calculated crack tip J

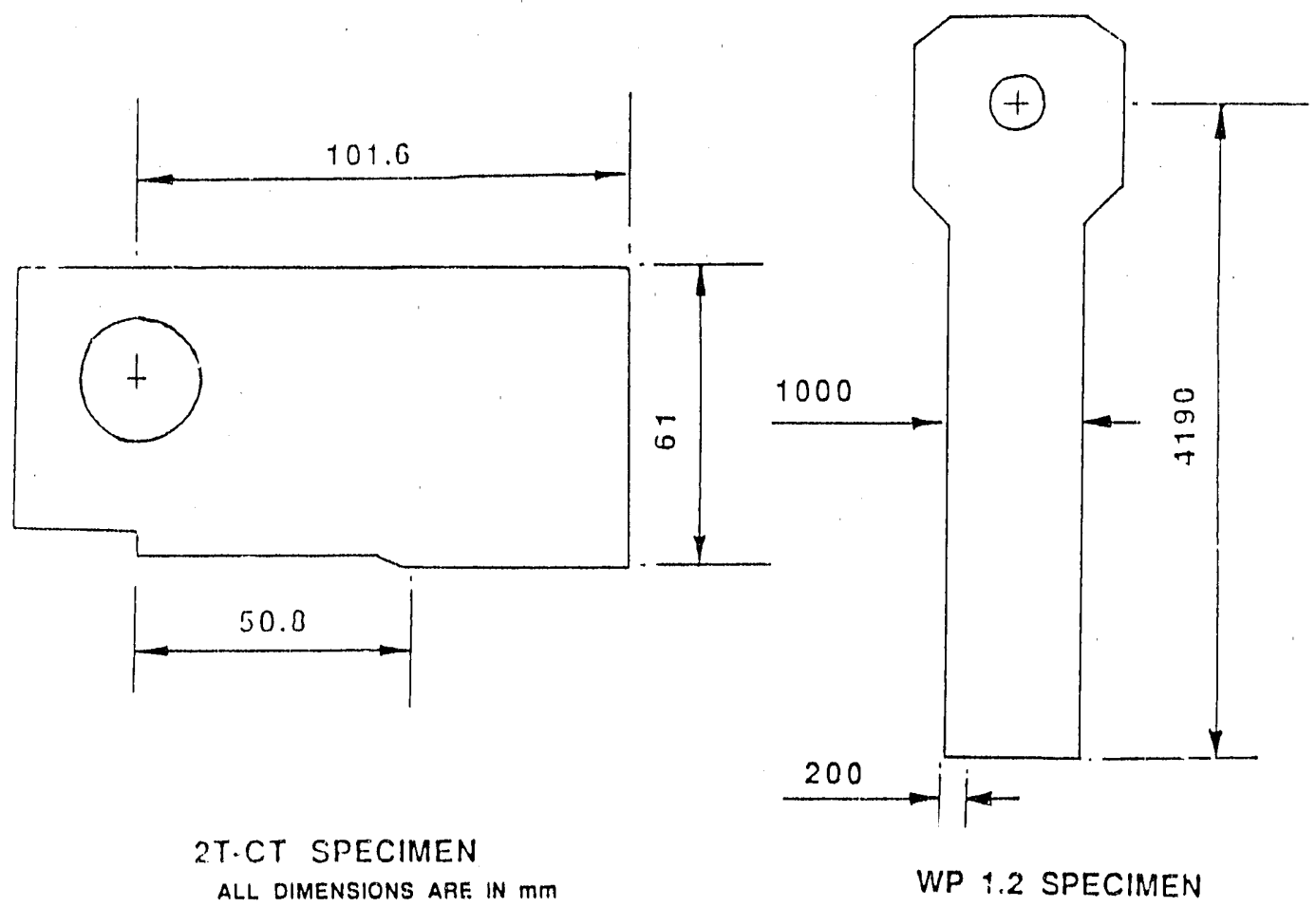

Fig. 11. Analysis models used in this study represent fracture-toughness test specimens differing widely in both geometry and size. 


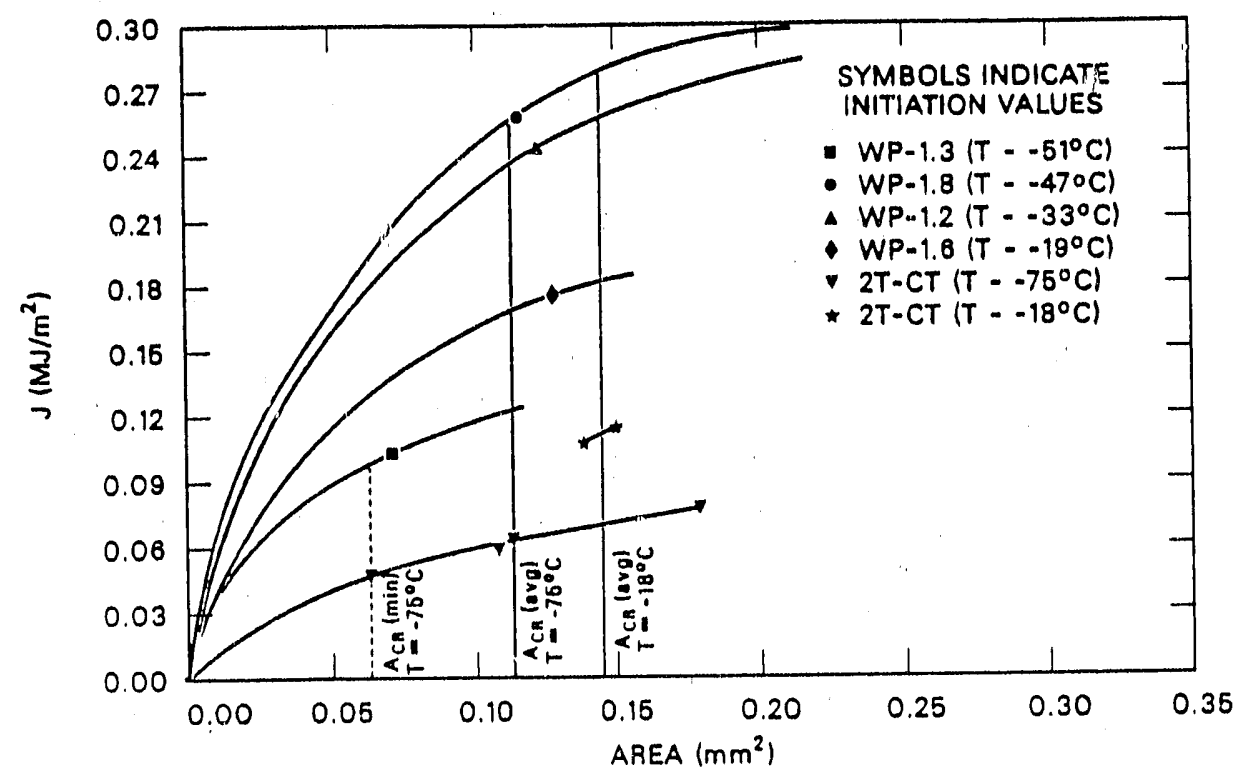

Fig. 12. Detailed 2-D and 3-D finite-element models of the wide-plate and compact-test specimens were used in an evaluation of potential supplementary fracture toughness parameters.

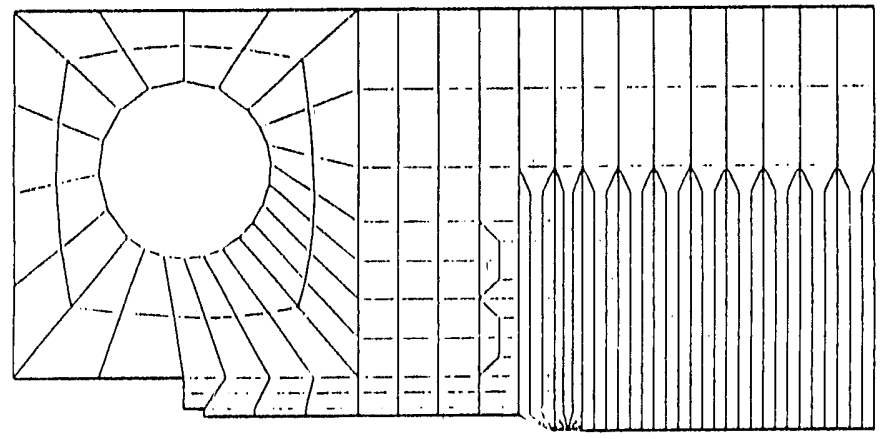

1052 NODES

500 ELEMENTS

7542 NODES 1409 ELEMENTS

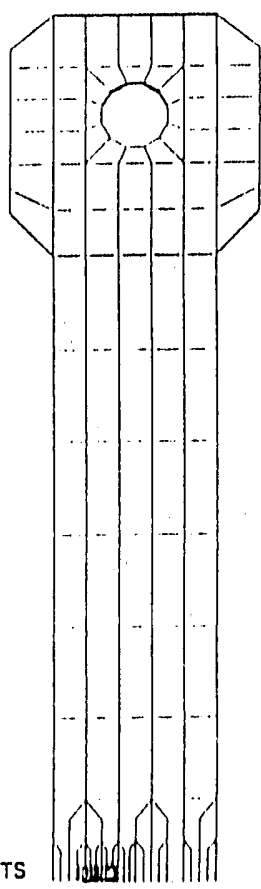

Fig. 13. Initial results show an improved transferability of fracture-toughness data using an additional parameter based on the crack-tip area enclosed within a stress contour corresponding with Hahn's estimate of the cleavage crack- propagation stress for ferrite grains (1380 MPa). 
integral plotted as a function of the area within the critical crack-tip stress contour. Each of the four wide-plate specimens analyzed is seen to produce a unique J-ACR curve. The upper curves are for WP-1.8, which was performed on a $15.24 \mathrm{~cm}(6$ in.) plate with a chevron crack front configuration at $-47^{\circ} \mathrm{C}$ and WP-1.2, in which a $10.16-\mathrm{cm}$-plate (4 in.) without chevrons was tested at $-33^{\circ} \mathrm{C}$. RTNDT for the A533B material used in these tests was $-23^{\circ} \mathrm{C}\left(-73^{\circ} \mathrm{F}\right)$. Fracture loads for the WP- 1.8 and 1.2 specimens were $26.5 \mathrm{MN}\left(5.96 \times 10^{6} \mathrm{lb}\right)$ and $18.9 \mathrm{MN}\left(4.25 \times 10^{6}\right.$ lb), respectively. The lower wide-plate specimen curves in Fig. 13 are for specimens 1.3 and 1.6, both of which were $10.16 \mathrm{~cm}$ (4 in.) wide specimens with a chevron crack-front configuration. Symbols on the curves denoie the point of fracture in each test.

The lower two curves in Fig. 13 are from the analyses of the compact-test specimens used to characterize material properties for the A533B wide-plate specimens. Again, the symbols on these curves denote specimen failure points. Verticals erected through the midpoint of $t$ characterization results for test temperatures of $-18^{\circ} \mathrm{C}$ and $-75^{\circ} \mathrm{C}$ define a range of areas $\left(A_{C R}\right)$ within the critical crack-tip stress contour. The significance of this area $\left(A_{C R}\right)$ as a potential auxiliary fracture-toughness correlation parameter derives from the fact that 3 of the 4 wide-plate specimens, which were tested at temperatures in the range $-75^{\circ} \mathrm{C}<\mathrm{T}<-18^{\circ} \mathrm{C}$, failed when the calculated crack tip $A_{C R}$ values were within the range of $A_{C R}$ values derived from small specimen tests conducted at $-75^{\circ} \mathrm{C}$ and $-18^{\circ} \mathrm{C}$. The remaining wide-plate specimen (WP-1.3) failed at an $A_{C R}$ value within the scatter band for the compact test specimen $A_{C R}$ values at $-75^{\circ} \mathrm{C}$.

The area within the critical crack tip stress contour $\left(A_{C R}\right)$ shows promise as an auxiliary fracturetoughness correlation parameter to improve the accuracy of fracture predictions involving specimen size related fracture toughness data transfer. It is evident from the scatter of results from the compact test specimens, however, that further work is required to develop these initial results into a useful auxiliary fracture parameter for use in pressure vessel analysis. Development of the $A_{C R}$ auxiliary fracture toughness correlation parameter is continuing within the HSST Program.

\subsection{Circumferential Cracks}

A review of issues associated with the analysis of fracture margins for circumferential cracks in reactor pressure vessels was given in Ref. 22. One of the open issues identified was the effect of a positive strain parallel to the crack front on the crack initiation toughness $\mathrm{KIc}$. An investigation of this condition, which is illustrated in Fig. 14, is the subject of an ongoing element of the HSST Program.

Investigation of the effects of positive out-of-plane strain effects is proceeding using a fine-mesh 3D elastic-plastic finite-element analysis of a compact test specimen slice to predict the effect on crack-tip stress and strain contours. Auxiliary crack-tip fracture-correlation parameters, including the $A_{C . R}$ parameter discussed previously, are then used to predict the effect of out-of-plane strains on crack-initiation toughness. Available plane- stress and plane-strain fracture-toughness data provide a means of validating the models used in the range $\varepsilon_{z} \leq 0.0$.

Figure 15 shows the geometry of the finite-element model used in this study. The model represents a $2.0 \mathrm{~mm}(0.08 \mathrm{in}$.) thick slice from a $1 \mathrm{~T}$ compact-test specimen. The region immediately surrounding the crack tip is modelled in a fine-mesh fan configuration to provide the required definition of crack tip stress and strain contours. Generalized plane-strain boundary conditions were used to impose out-of-plane strains $\left(\varepsilon_{z}\right)$ on the model. Both loads and boundary displacements were applied incrementally up to their maximum values. The maximum load of $0.035 \mathrm{MN}$ (7.9 kips) corresponds to the fracture load of one of the 1T-CT specimens used to 


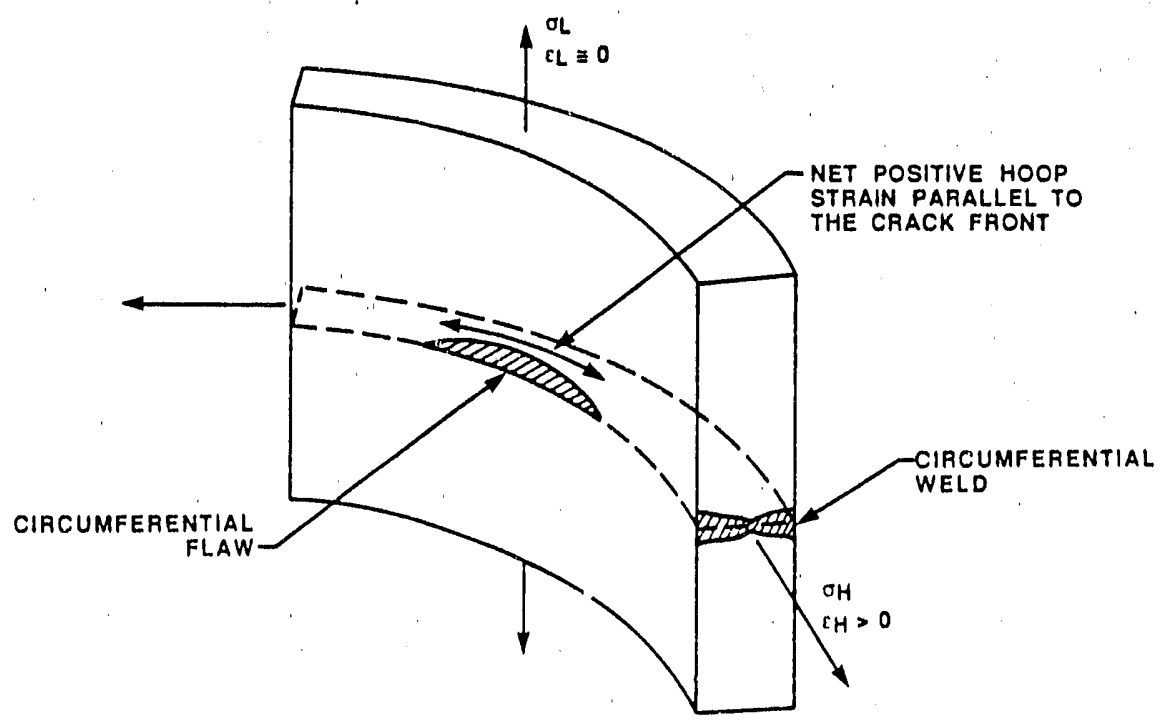

Fig. 14. Positive-hoop strains parallel to the crack front coupled with a higher hydrostatic/deviatoric stress ratio may reduce the material ductile tearing toughness for circumferential flaws below that associated with axial flaws.

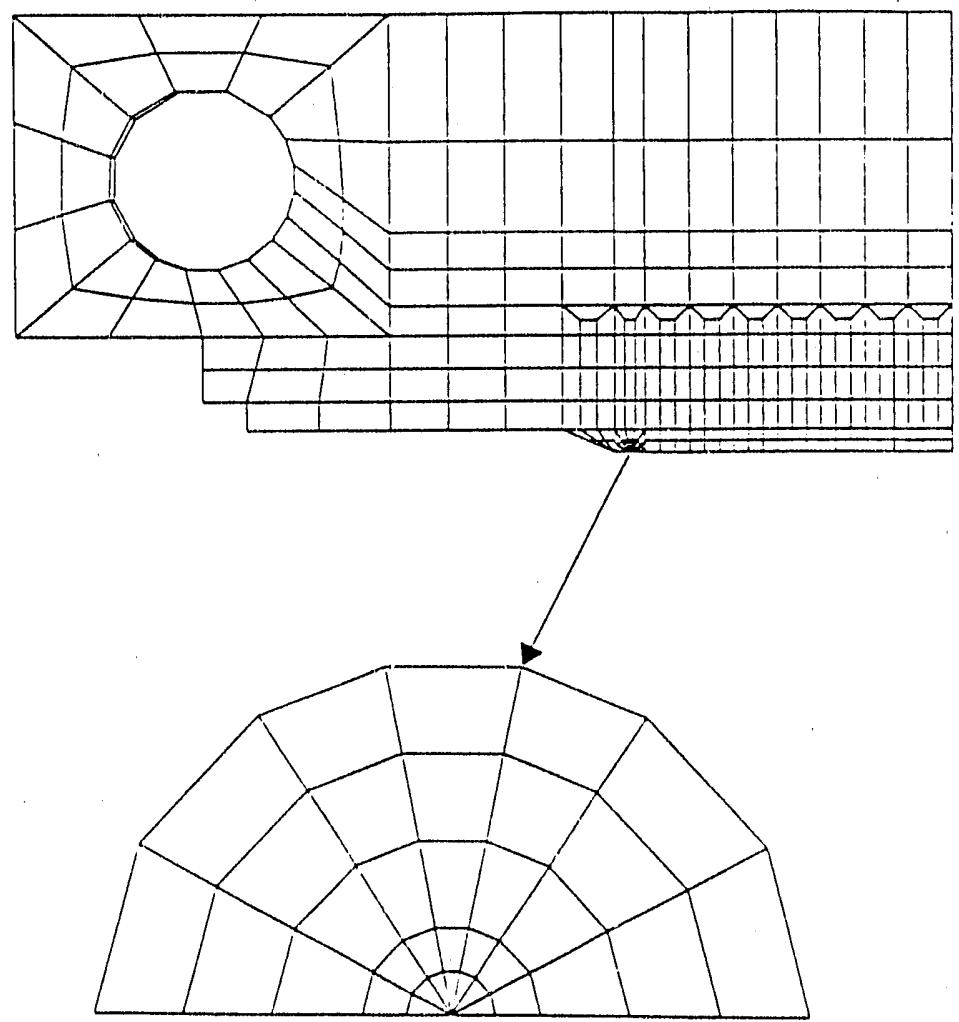

Fig. 15. A thin three-dimensional model of a 1T-CT specimen is used to study out-of-plane strain effects. 
characterize material properties for the Series 1 wide-plate tests. A second specimen failed at an applied load of $0.028 \mathrm{MN}$ (6.3 kips). Both loading conditions were analyzed in this study. Transverse strains of $\pm 0.14 \%$ and $\pm 0.114 \%$ were applied for the $0.035 \mathrm{MN}$ - and $0.028 \mathrm{MN}$ loading conditions, respectively.

Results from the ADINA analysis of the $0.035 \mathrm{MN}$ CT-specimen slice model are reproduced from Ref. 19 in Fig. 16. Significant reductions in both the area of the plastic zone and the crack-tip plastic-zone radius are seen to occur as the out-of-plane strain $\left(\varepsilon_{z}\right)$ transitions from $-0.14 \%$ to $+0.14 \%$. A reverse trend is observed in the case of the area $A_{C R}$ within the critical crack -tip stress contour.

Plots of the crack-tip $J$ as a function of $A_{C R}$ are given in Fig. 17 for each of the out-of-plane generalized plane-strain conditions analyzed for the $0.028 \mathrm{MN}$ CT specimen. These results indicate that a positive out-of-plane strain $\left(\varepsilon_{Z}=0.114 \%\right)$ produces a reduction in crack-tip $J$ at the $A_{\mathrm{CR}}$ value corresponding with $\mathrm{JIC}_{\mathrm{IC}}$ in the $\varepsilon_{Z}=0$ specimen. An opposite result is seen to exist for the case of the $\varepsilon_{Z}=-0.114 \%$ analysis. These results indicate some reduction in fracture toughness under conditions similar to those existing in the circumferential weld of a reactor pressure vessel.

$A_{C R}$ appears to have the potential for development into an auxiliary correlation parameter which can be used to improve fracture predictions involving fracture-data transfer. Further wurk is required however to develop and validate this concept. In particular, the performance of the $A_{C R}$ parameter needs to be tested further in the plane stress $\left(-\varepsilon_{\mathbf{Z}}\right)$ to plane-strain $\left(\varepsilon_{\mathbf{Z}}=0\right)$ domain using available fracture-toughness test data to check the consistency of its predictions and establish performance limits. This work is planned as a continuing element of the HSST Program.
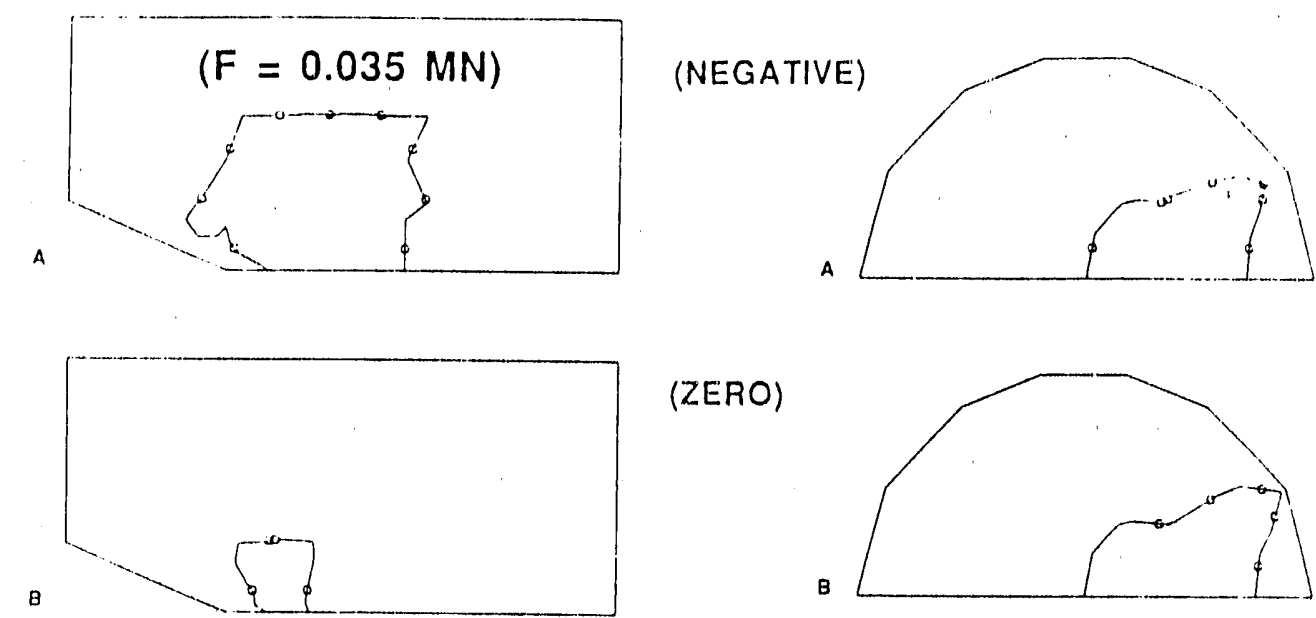

(ZERO)
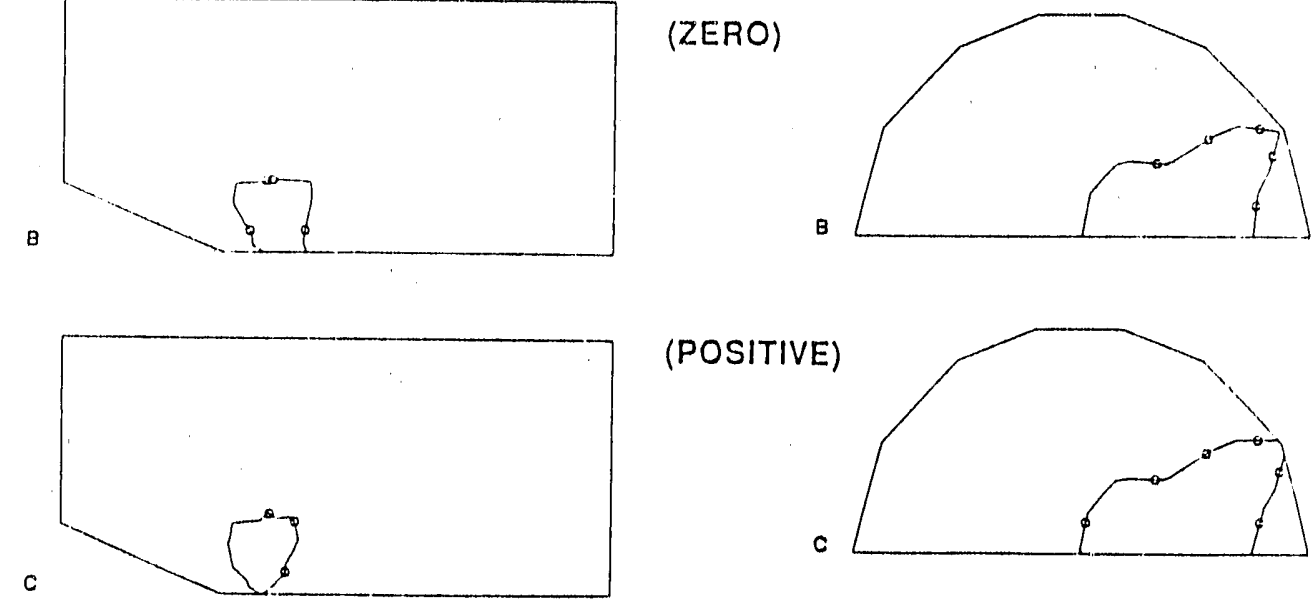

(POSITIVE)

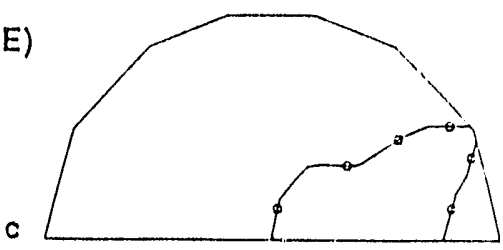

Fig. 16. The plastic-zone area decreases and area enclosed within a given principal stress contour increases with increasing out-of-plane strain. 


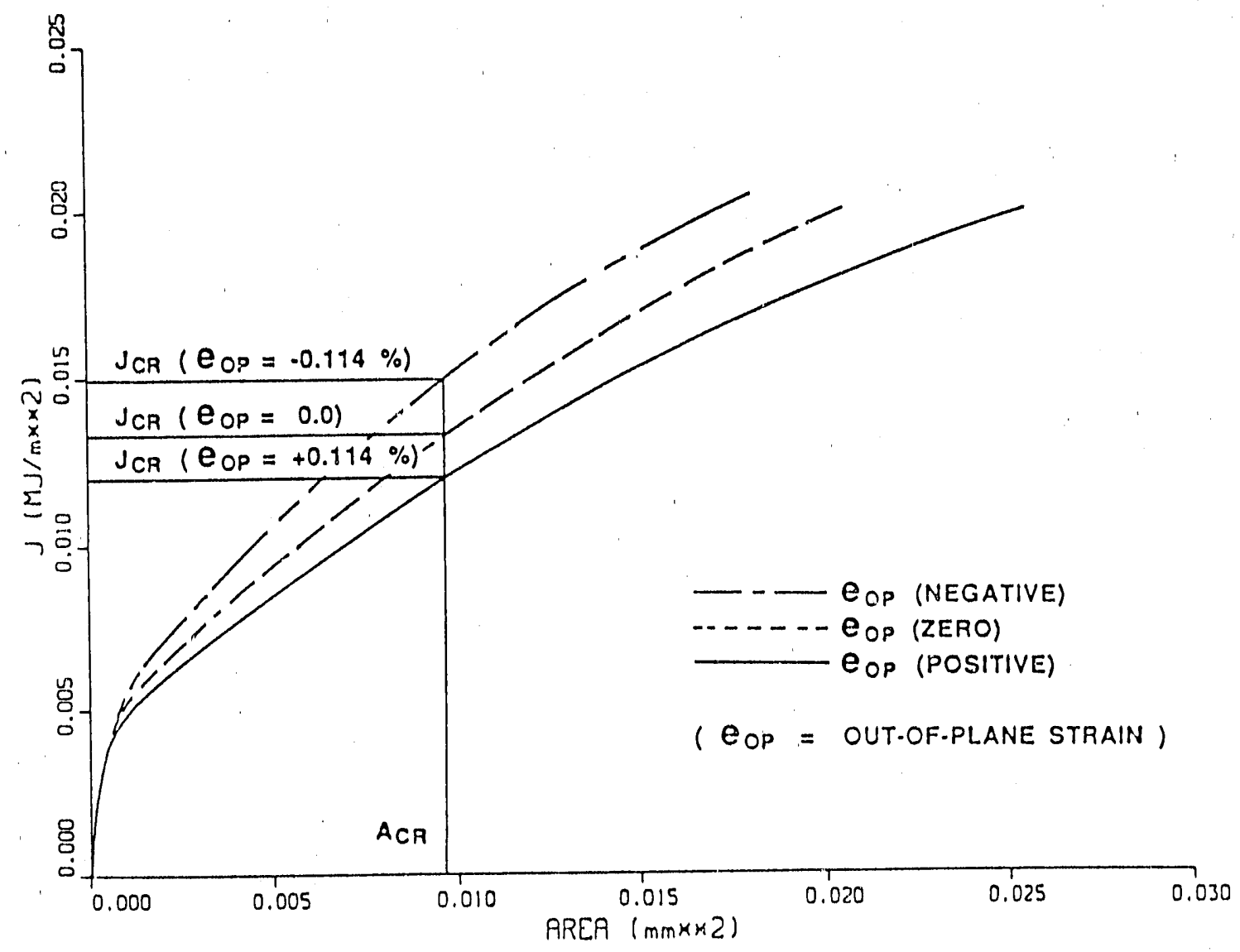

Fig. 17. The applied J required for initiation is shown to be a function of the out-of-plane strain condition.

Examination of the plots of Fig. 16. shows that the zone of plastic straining surrounding the crack tip is also influenced significantly by the application of out-of-plane $\left(\varepsilon_{z}\right)$ strains. The width of the plastic zone, along the crack-extension path $\left(r_{y}\right)$, is seen to be particularly sensitive to the generalized plane-strain boundary condition $\left(\varepsilon_{Z}\right)$

A relationship between the plastic zone size $\left(r_{y}\right)$ at instability and the material fracture toughness is developed in Ref. 23. Application of this relationship provides an additional means of assessing the effect of a positive out-of-plane strain on fracture toughness. The relationship has the following form:

$$
r_{y}=\frac{1}{\beta \cdot \pi}\left(\frac{K_{1}}{\sigma_{y}}\right)^{2}
$$

where $\beta$ is a constraint factor having a value of 2.0 for plane stress and 6.0 for plane-strain conditions, and $\sigma_{\mathrm{y}}$ is the material-yield stress. 
Application of Eq. (6) to the evaluation of the plastic zone radius ( $r_{y}$ ) data of Fig. 16 requires development of $\beta$ factors for conditions other than those described above. This development has not yet been completed. It is apparent however from the results shown in Fig. 16 that the ratio of crack tip $r_{y}$ values for the case of $\varepsilon_{z}=-0.14 \%$ and $\varepsilon_{z}=0 \%$ is close to 3.0 . Under these conditions the value of $K_{I}$ at instability for the $\varepsilon_{z}=-0.14 \%$ case would approach the plane stress fracture toughness $\mathrm{K}_{\mathrm{C}}$, which is significantly greater than the plane strain fracture toughness $\mathrm{K}_{\mathrm{Ic}}$ associated with the $\varepsilon_{z}=0 \%$.case. The factor of 3 increase in ry between the $\varepsilon_{z}=0 \%$ and $\varepsilon_{z}=-0.14 \%$ cases is therefore associated with a fracture toughness increase of the order of $\mathrm{K}_{\mathrm{C}} / \mathrm{K}_{\mathrm{Ic}}$. Application of similar reasoning to the $\varepsilon_{z}=+0.14 \%$ case, where the ratio $r_{y}+/$ ryo is approximately 0.15 , would indicate that the fracture toughness for the $\varepsilon_{z}=0.14 \%$ case could be significantly lower than that for the plane strain $\left(\varepsilon_{z}=0 \%\right.$.) case.

It is apparent from the prior discussion that of the two candidate auxiliary fracture- toughnesscorrelation parameters under evaluation ( $A_{C R}$ and $r_{y}$ ) currently indicate significantly differing impacts for a positive out-of-plane strain. Further work is required to resolve these apparently conflicting results. It is anticipated that large-scale fracture tests under conditions of biaxial loading will be required to refine and validate an auxiliary fracture toughness parameter. What limited test data exist on fracture under biaxial loading conditions (Refs. 24 and 25) tend to indicate a much weaker influence of out-of-plane strains on $\mathrm{K}_{\mathrm{Ic}}$ than would be inferred form the plastic-zone radius correlation.

The interim conclusion from this work is that the auxiliary fracture-toughness-correlation parameters currently under investigation have the potential to provide a guide to the adjustment of fracture toughness required (if any) for the analysis of circumferential cracks. Considerable further development is required however before the auxiliary fracture-toughness-correlation parameter can be considered a useful fracture-analysis tool.

\subsection{Ductile Tearing}

Ductile tearing in advance of cleavage fracture has been shown in both analysis (Ref. 26) and test (Ref. 27) to be a fracture mode of concern in the PTS analysis of reactor vessels containing low upper-shelf (LUS) weld material. This material exists in 17 vessels currently in serviced within the U.S. electric utility system (Ref. 28).

In the context of a PTS analysis the primary concerns relating to ductile tearing are (a) modification of the initial-flaw geometry, (b) a potential decrease in the cleavage-crack initiation toughness due to the strain-rate effects induced by ductile tearing and, (c) ductile tearing instability as the ultimate reactor vessel failure mode.

A comprehensive review of the state-of-the-art of ductile tearing technology was conducted in an International Workshop held May 8-10, 1990, in Boston, Mass. The workshop was organized by the OECD Committee on Safety of Nuclear Installations/Fracture Analysis Group (CSNI/FAG). An effective evaluation of the state-of-the-art of ductile tearing technology was achieved by means of comparing analyses, performed by the workshop attendees, of large-scale fracture experiments from a number of the participating countries.

Results from the CSNI/FAG Workshop are still under evaluation by the workshop participants. No consensus assessment of the state-of-the-art of ductile tearing technology is available from the 
workshop at the time of writing. It appears likely, however, that some of the fracture experiments analyzed involved crack-tip behavior which may not be adequately characterized by a sing'e ( $J$ integral) fracture-correlation parameter.

Heavy-Section Steel Technology-program efforts directed at resolution of the ductile 1 issue are centered on the development of a crack tip micro-mechanical model. The it, this development, which is an extension of the model development described briefly in Sec. to produce a model which can predict tearing based upon fundamental material properties. Such a model should have the capability to predict tearing behavior in conditions where single-parameter characterization of ductile tearing behavior are no longer adequate.

Development and validation of ductile tearing technology improvements to resolve the issues currently identified appears to be unavoidably a long range process. Interim assessments of the effects of ductile tearing may be required to meet near-term requirements for PTS evaluations. A recently completed HSST program study of the impact of ductile tearing on the utility of extended crack-arrest-toughness curves (Ref. 29) provides an example of such an interim assessment. The study of Ref. 29 showed that ductile tearing effectively negates most of the PTS analysis advantages deriving from an extended cleavage crack-arrest-toughness curve. Similar sensitivity evaluations of the effect on a PTS analysis of ductile tearing in advance of cleavage fracture are included in the near-term HSST Program plan.

\section{Cladding}

Cladding has typically been regarded as a tough inner skin to the reactor vessel with a capability to impart an additional increment of fracture margin by acting to reduce the crack-tip opening of submerged cracks. This condition is illustrated in Fig. 18(a). While thermal expansion and heattransfer properties of the stainless steel cladding were included in the PTS analysis of Ref. 7, effects of the enhanced cleavage fracture toughness of cladding were conservatively neglected.

Interest in cladding derives from its potential influence on crack initiation in the vessel shell structural material. Results from fracture tests on clad plates (Ref. 30) have shown that a fastrunning crack will tunnel under cladding. Cladding, therefore, appears to have only a minor influence on structural margins once cleavage cracking of the shell material has been initiatiated.

Data generated recently in the reactor materials irradiation program (Ref. 5) have raised a concern relative to a possible negative effect of cladding on pressure vessel fracture margins during a PTS event. The concern derives from the low ductile tearing toughness of irradiated cladding. Figure 19 shows the test results of concern. Tearing toughness of irradiated stainless steel cladding is seen to be similar to that of irradiated LUS-weld material, and substantially less than that of irradiated A533B vessel shell material. A concern exists therefore that tearing could initiate in the cladding and convert to cleavage fracture at the cladding-base material interface. Strain-rate effects induced by the tearing process add to the cleavage fracture-initiation concern.

The objective for the initial phase of this study is to determine the potential for clad ductile tearing initiation in advance of cleavage-fracture initiation in the base material for two flaw configurations of particular interest in a PTS analysis. These are (a) the sernielliptical-surface flaw and (b) the two-dimensional subclad flaw. Conceptual features of these flaws are illustrated in Fig. 18. Initial evaluations have focused on the semielliptical-surface flaw. 


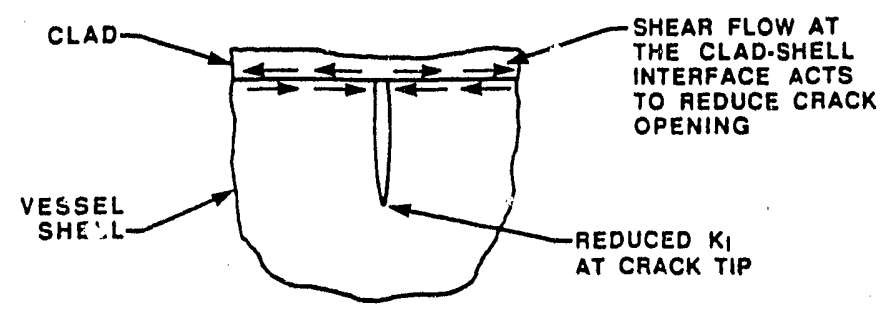

(a) POSITIVE CLAD POTENTIAL FOR SUB.CLAD FLAWS

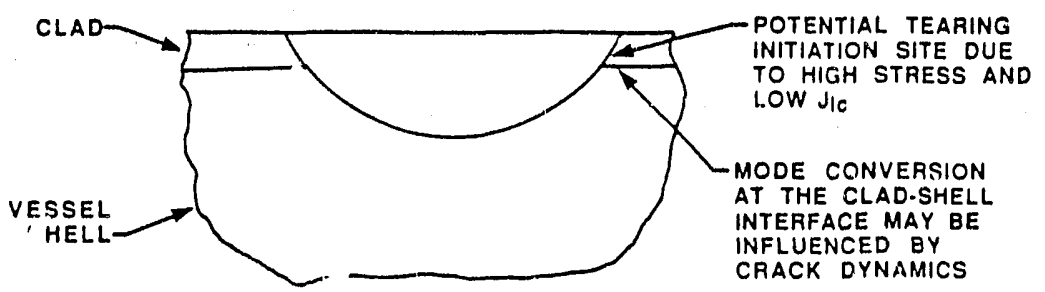

(b) NEGHTIVE CLAD POTENTIAL

Fig. 18. Effects of the vessel cladding are not yet fully included in the reactor vessel PTS analysis models (OCA-P). Additional research is required to determine if their introduction will have a net positive or negative effect on the calculated reactor vessel failure probability.

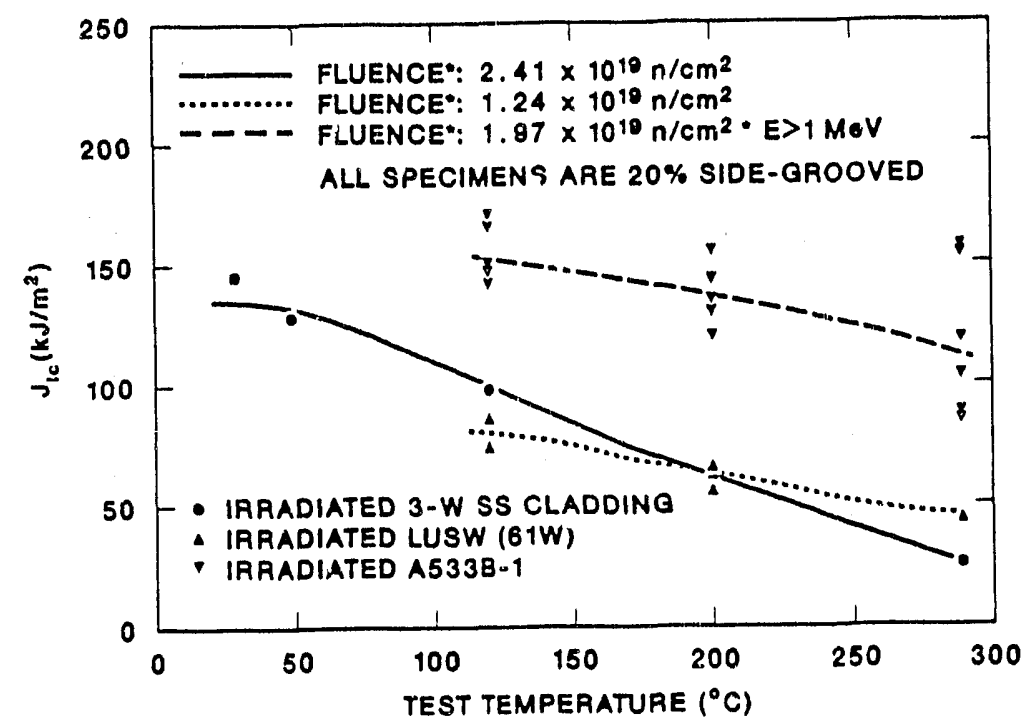

Fig. 19. Recently completed tests to measure the ductile tearing toughness of reactor vessel materials have shown ductile-tearing initiation toughness of both LUS weld material and cladding in the irradiated condition to be approximately half that of irradiated A533B material. 
Figure 20 shows the 3D elastic-plastic finite-element model used in the evaluation of clad-tearing events in surface flaws. A 6:1 aspect ratio semielliptical surface flaw with a maximum depth of $1.78 \mathrm{~cm}(0.7 \mathrm{in}$.) was used in this evaluation. Generalized plane-strain boundary conditions were imposed on the vertical surfaces of the model in order to simulate a level of deformation restraint consistent with that encountered in a reactor pressure vessel shell. Mechanical and physical properties for Type 304 stainless steel and A533B low-alloy steel were used for the cladding and base material, respectively.

Transient pressure and temperature loading used in the analysis are given in Fig. 21. The loading condition time histories shown in Fig. 21 were derived from an idealization of the Rancho Seco PTS transient. They provide therefore a realistic basis for assessing the potential for clad-tearing initiation under PTS-loading conditions.

Crack-tip stress-intensity factors at the clad-base metal interface (Point 3 ) on the crack front are shown plotted in Fig. 22. Results are plotted for both elastic and elastic-plastic analyses of the model. Note that elastic-plastic analysis results in a significant reduction in the effective crack-tip stress-intensity factor at this location. The bulk of this reduction is due to plastic deformation in the cladding, since the yield stress for the cladding at the temperature of interest in this analysis is approximately $138 \mathrm{MPa}$ (20. ksi).

Estimated lower-bound $\mathrm{KJc}$-tearing-toughness curves for cladding, LUS-weld metal and A533B plate material are shown superimposed on the applied $\mathrm{KJ}$ curves in Fig. 22. These materials

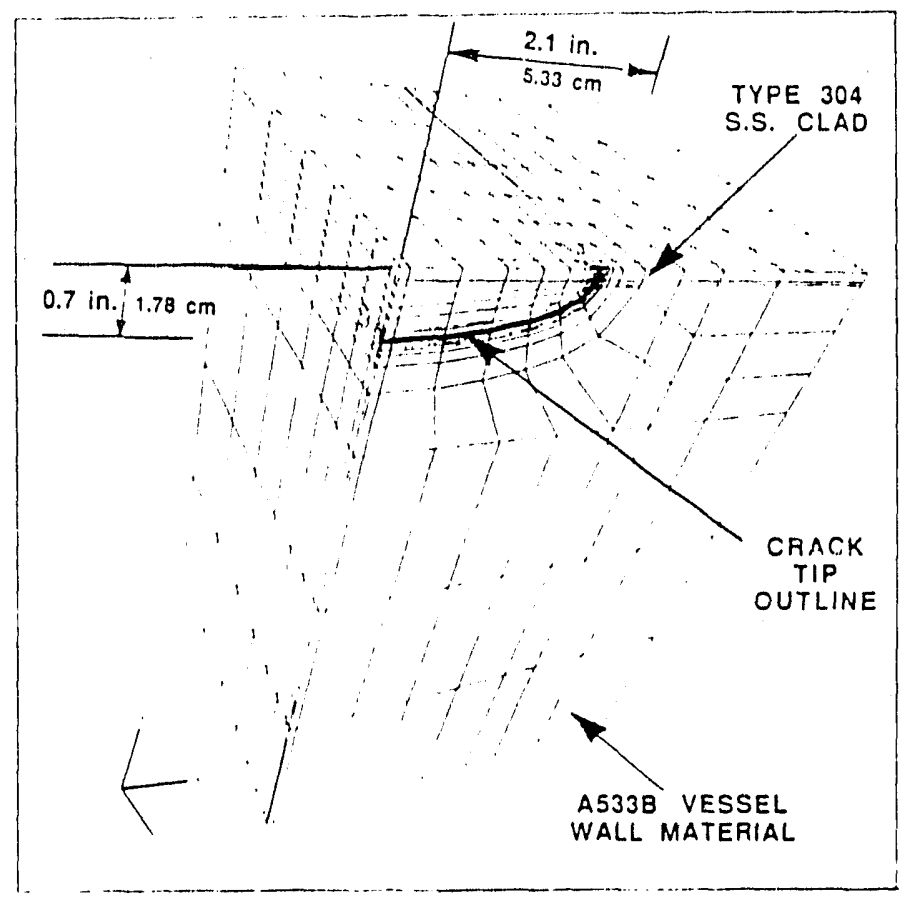

Fig. 20. A 3-D elastic-plastic finite element model was used to evaluate the effect of low cladding-tearing toughness on crack initiation under PTS-transient loading. The analysis used a bilinear representation of the stress-strain curve. 


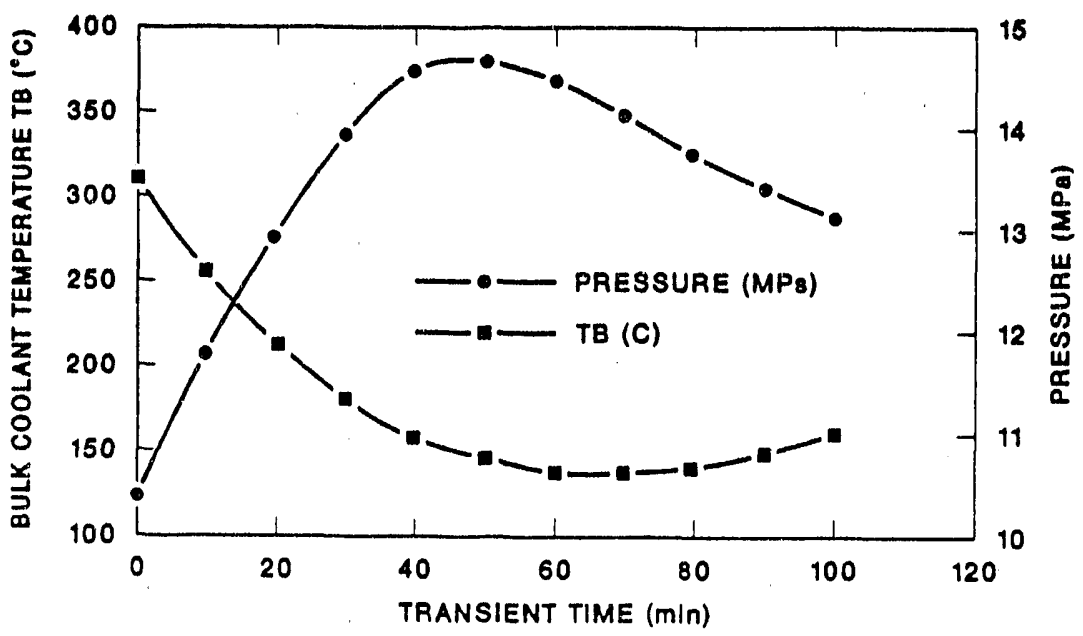

Fig. 21. The "Rancho Seco" PTS transient was used in the preliminary evaluation of the effect of low clad-tearing toughness on crack initiation in surface flaws.

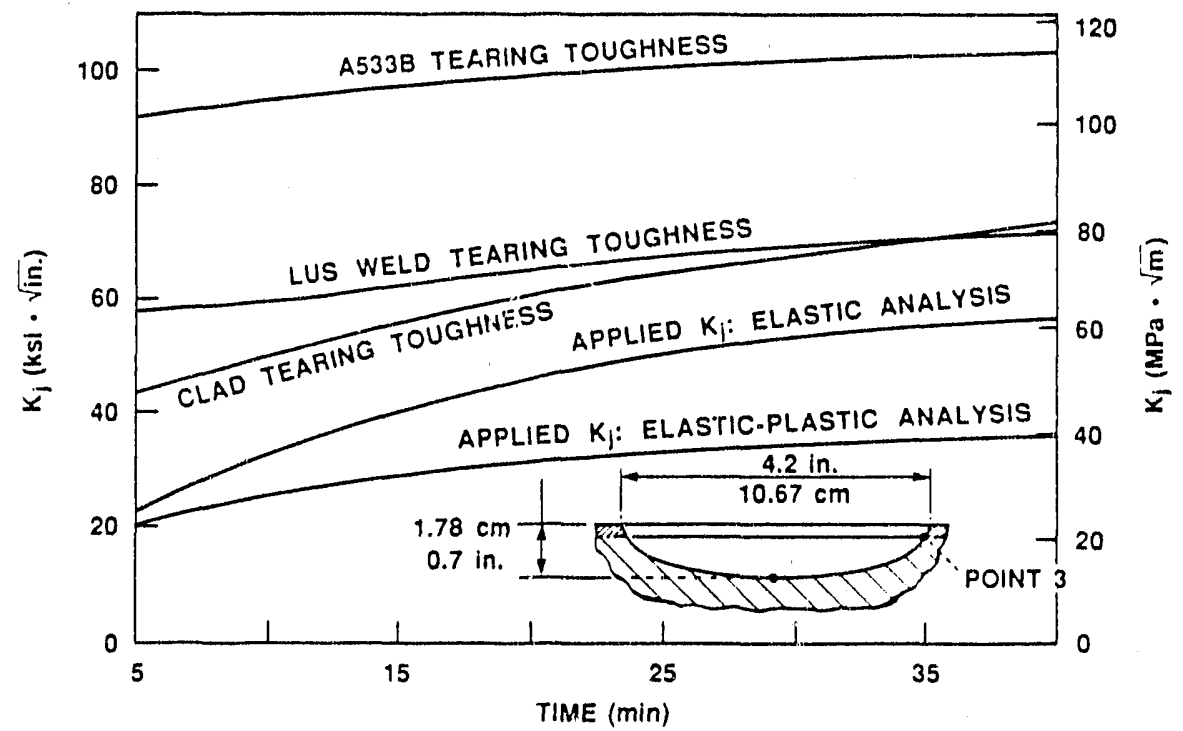

Fig. 22. The applied crack tip stress-intensity factor $(\mathrm{KJ})$ at the clad-base metal interface remains significantly below the estimated $-2 \sigma$-tearing toughness curve for both cladding and LUS weld metal throughout the transient. Plasticity effects significantly reduce the magnitude of the applied $\mathrm{KJ}$ at this location (Point 3 ).

toughness curves were derived from the ductile tearing toughness curves of Fig. 19 by means of (a) expressing the ductile tearing toughness $\mathrm{J}$ as an equivalent fracture toughness $\mathrm{KJ}$ using the relationship $K_{J}=\sqrt{E . J}$ and (b) reducing the mean fracture-toughness curves from step (a) by the factor $1 / 1.43$ to obtain estimated $-2 \sigma$ curves. The factor $1 / 1.43$ derives from the analysis of the ASME Code fracture-toughness data base reported in Ref. 7 . Implicit in the above procedure is the assumption that the ductile tearing toughness curves of Fig. 19 represent the mean tearing toughness of the material. 
It is evident from the curves of Fig. 22 that the applied $\mathrm{KJ}$ value at the clad-base material interface does not come close to the estimated $-2 \sigma$-clad-tearing toughness curve at anytime during the transient. This observation holds for the $\mathrm{KJ}$ curves generated from both elastic and elastic-plastic analysis results. Based upon the magnitude of the tearing margins derived from the curves of Fig. 22 , it appears unlikely that propagation of surface cracks into the base material could be induced by the low ductile-tearing toughness of irradiated stainless steel cladding material.

Evaluation of the effect of low clad-tearing toughness on the response of subclad flaws to PTS loading is to be addressed in the next phase of the task. The configuration of concern is illustrated in Fig. 18 (a). The role of cladding in this configuration is to reduce the crack tip KI value. Cladding is therefore characterized as having a beneficial impact on the fracture response of subclad flaws to PTS loading. This beneficial effect is retained however only while the cladding above the crack remains integral. Should rupture of the cladding occur, it could result in a relatively rapid increase in the crack tip stress intensity factor. Adverse consequences associated with clad rupture include (a) negating benefits from warm prestressing, (b) delaying the time for crack initiation such that the vessel wall temperature has decreased with an associated reduction in both $\mathrm{K}_{\mathrm{Ic}}$ and $\mathrm{K}_{\mathrm{Ia}}$, and (c) potential reduction in $\mathrm{K}_{\mathrm{Ic}}$ due to the introduction of strain-rate effects. The significance of the subclad flaw issue has been further emphasized by reports from the French nuclear power program (Ref. 31) of subclad material segregation in ring-forged reactor vessel shell courses.

In addition to its role in assessing the potential for clad-tearing-induced surface propagation of a surface crack, the analysis model of Fig. 20 also provides an insight into the relative potential for ductile tearing and cleavage fracture to trigger crack initiation at the deepest point on the crack front. Results for this point [Point 11] are shown plotted in Fig. 23. The LUS-tearing-toughness curve approaches the applied $\mathrm{KJ}$ curve relatively early in the transient at a time when $\mathrm{KJ}$ is

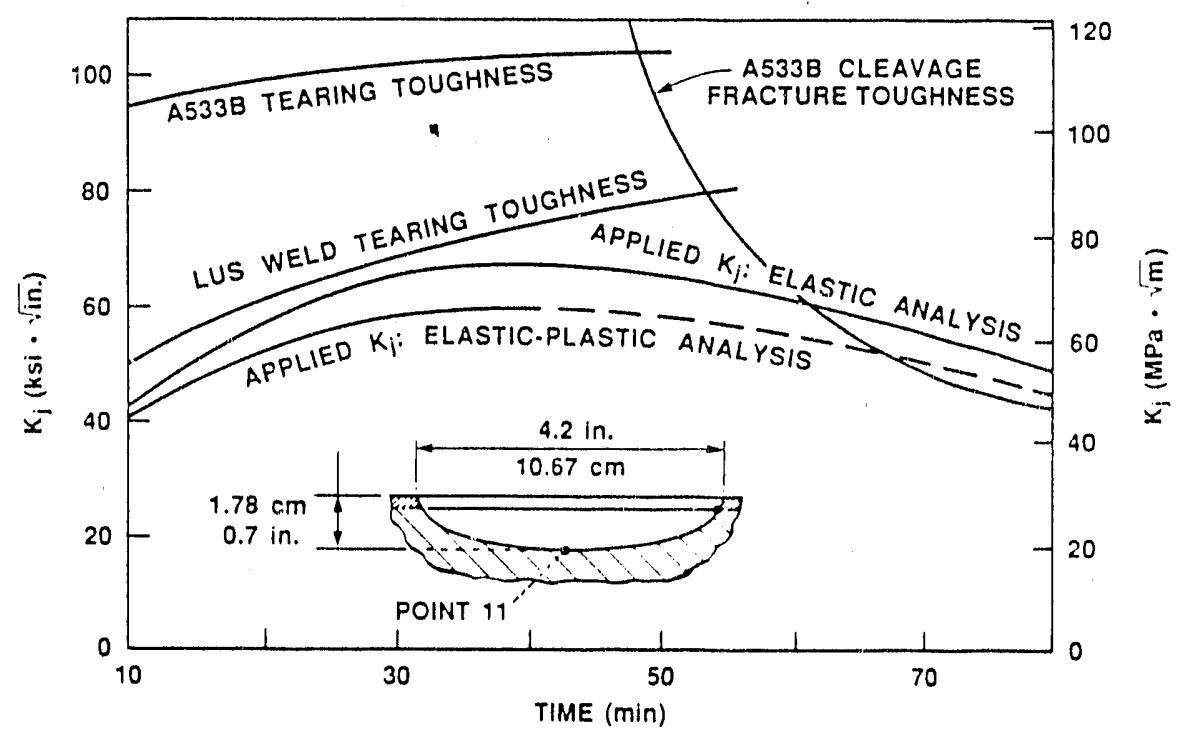

Fig.23 Based upon an estimated $-2 \sigma$ tearing toughness curve for LUS material, tearing in advance of cleavage fracture would not be predicted for the transient analyzed. Note that the effect of plasticity on the calculated crack tip stress-intensity factor $\mathrm{KJ}$ remains significant at this point (11) on the crack front. 
positive. It is conceivable that an alternate transient could result in tearing initiation. The cleavage toughness $-2 \sigma$ curve intersects the applied $\mathrm{KJ}$ curve, but does so in a region where $\mathrm{KJ}$ is negative. Cleavage-crack initiation should therefore be inhibited by the warm-prestressing effect.

The conclusion drawn from the curves of Fig. 23 is that ductile tearing followed by cleavage may be the most probable mode of crack initiation for vessels containing LUS-weld material. This conclusion is consistent with results obtained in the PTSE-2 thermal-shock tests, in which ductile tearing preceded the onset of cleavage fracture (Ref. 27). These results serve to emphasize the need for timely development and validation of an improved ductile-tearing technology for use in the analysis of PTS transients.

\section{Conclusions}

HSST program research and development activities described in the previous sections are not yet complete. It follows therefore that only interim conclusions are available at this time. Interim conclusions are of some value however in that they indicate potential directions for PTS analysis technology development. The most significant of these interim conclusions are as follows.

(a) The input flaw-distribution curve has a dominant influence on the normalized, cumulative crack-initiation curve. By comparison, differences between the dominant transients have second-order effect on the curve.

(b) The spatial distribution of flaws within the reactor vessel wall has not yet been characterized.

(c) Limited vessel weld-inspection data indicate that the flaw density in the critical inner region of the vessel weld may be higher than currently assumed by a factor in excess of one order of magnitude.

(d) The fracture toughness for shallow flaws is expected to be significantly elevated due to the release of crack-tip constraint. Pilot analyses have shown that an elevated shallowflaw fracture toughness can significantly reduce the predicted number of crack initiations.

(e) Supplementary correlation parameters can improve the transferability of fracturetoughness data from small-scale specimens to large-scale application. Implications of this development for the fracture analysis of circumferential flaws remain unclear at this time.

(f) Ductile-tearing prediction remains a problem area in the PTS analysis of LUS vessels. Inclusion of ductile tearing in advance of cleavage fracture appears to be a mandatory requirement for the PTS analysis of reactor vessels containing LUS-weld material.

(g) Preliminary evaluations indicate that low clad-tearing toughness should not act as a trigger for cleavage initiation in through-clad finite-length flaws.

\section{Acknowledgements}

The author wishes to acknowledge contributions made by R. D. Cheverton, K. V. Cook, and J. G. Merkle (consultation): B. R. Bass, T. L. Dickson, J. Keeney-Walker, D. K. M. Shum 
and T. J. Theiss (analysis): G. C. Robinson (shallow-flaw testing): Professor S. T. Rolfe of the University of Kansas (shallow-flaw fracture toughness data and discussions): Linda Dockery (computer graphics) and Marge Taylor (draft preparation): and M. E. Mayfield (HSST Program Monitor) and C. Z. Serpan (Chief, Materials Engineering Branch) of the NRC for suggesting and supporting this review of HSST program developments.

\section{References}

1. "Neutron Embrittled Reactors Worry NRC, " Science News, Vol. 119, p. 390 (June 20, 1981).

2. "Vessel Embrittlement Clouds Future of Finland's Loviisa," Nucleonics Week, pp. 5-6 (January 12, 1989).

3. A. L. Hiser, F. J. Loss, and B. H. Menke, J-R Curve Characterization of Irradiated Low Upper Shelf Welds, Materials Engineering Associates, Inc., Lanham, Md. for U.S. Nuclear Regulatory Commission, NUREG/CR-3506 (MEA-2028) April 1984.

4. R. K. Nanstad et al., "Effects on Radiation in $\mathrm{K}_{\mathrm{Ic}}$ Curves for High-Copper Welds," pp. 214-33 in Effects of Radiation on Materials: 14th International Symposium, Vol.2, ASTM STP 1046, ed. N. H. Packan, R. E. Stoller, and A. S. Kumar, American Society for Testing and Materials, Philadelphia, 1990.

5. F. M. Haggag, W. R. Corwin, and R. K. Nanstad, Irradiation Effects on Strength and Toughness of Three-Wire Series-Arc Stainless Steel Weld Overlay Cladding, USNRC NUREG/CR-5511 (ORNL/TM-11439), Oak Ridge National Laboratory, February 1990.

6. U.S. Nuclear Regulatory Guide 1.154, Format and Content of Plant-Specific PressurizedThermal-Shock Safety Analysis Report for Pressurized Water Reactors, U.S. Nuclear Regulatory Commission, Washington, DC, January 1987.

7. R. D. Cheverton and D. G. Ball, "Probabilistic Fracture-Mechanics Analysis of Potential Overcooling Sequences for H. B. Robinson Unit 2,", Chapter 5 of Pressurized-ThermalShock Evaluation of the H. B. Robinson Unit 2 Nuclear Power Plant, NUREG/CR-4183, Volume 1 (ORNL/TM-9597/V1), Martin Marietta Energy Systems, Inc., Oak Ridge Natl. Lab., September 1985.

8. U.S. Nuclear Regulatory Guide 1.99 (Rev.2), Radiation Embrittlement of Reactor Vessel Materials, USNRC, Washington, DC, `May 1988.

9. W. Marshall, United Kingdom Atomic Energy Authority, An Assessment of the Integrity of PWR Pressure Vessels, Report by a Study Group, October 1, 1976.

10. W. Marshall, United Kingdom Atomic Energy Authority, An Assessment of the Integrity of PWR Pressure Vessels, Second Report by a Study Group, March 1982.

11. Report on the Brittle Fracture of a High Pressure Boiler Drum at Cockenzie Power Station, South of Scotland Electricity Board, Jan. 1967. 
12, K. V. Cook and R. W. McClung, Martin Marietta Energy Systems, Inc., Oak Ridge Natl. Lab., Flaw Density Examinations of a Clad Boiling Water Reactor Pressure Vessel Segment, USNRC NUREG/CR-4860, Rev. 1, (ORNL/TM-10365/R1), Feb. 1988.

13. Frank Ammirato, Examinations of Midland RPV Plates, presented to Electric Power Research Institute NDE Subcommittee Meeting, Seattle, Washington, September 12, 1989.

14 N. F. Haines, S. Crutzen, and C. J. Vinche, "A Review of the Major PISC II RoundRobin Test Results," The British Journal of Non-Destructive Testing, Vol. 29, No. 6, November 1987.

15. W. A. Sorem, University of Kansas, The Effect of Specimen Size and Crack Depth on the Elastic-Plastic Fracture Toughness of a Low-Strength High-Strain Hardening Steel, Ph.D. Dissertation, May 1989.

16. J. A. Smith, Butler Manufacturing Co. and S. T. Rolfe, University of Kansas, The Effect of Crack Depth to Wiidth Ratio on the Elastic-Plastic Fracture Toughness of a HighStrength Low-Strain Hardening Steel, February 1990.

17. D. J. Naus et al., Martin Marietta Energy Systems, Inc., Oak Ridge Nati. Lab.,SEN Wide Plates Crack Arrest Tests Using A533 Grade B Steel Class 1 Material: WP-CE Test Series, USNRC Report NUREG/CR-5408 (ORNL/TM11269), November 1989.

18. D. J. Naus et al., Martin Marietta Energy Systems, Inc., Oak Ridge Natl. Lab.,CrackArrest Behavior in SEN Wide Plates of Quenched and Tempered A533 Grade B Steel Tested Under Nonisothermal Conditions, USNRC Report NUREG/CR-4930 (ORNL6388), August 1987.

19. D. K. M. Shum, J. G. Merkle, J. Keeney-Walker, and B. R. Bass, Martin Marietta Energy Systems, Inc., Oak Ridge Nati. Lab., Analytical Studies of Transverse Strain Effects on Fracture Toughness for Circumferentially Oriented Cracks, USNRC Report

20. G. T. Hahn, A. Gilbert, and C. N. Reid, "Model for Crack Propagation in Steel," J. Iron Steel Inst. (London) 202, pp. $677-684$ (August 1964).

21. K. J. Bathe, Massachusetts Institute of Technology, ADINA - A Finite Element Program and Automatic Dynamic Incremental Analysis, Report A-1, Cambridge, Mass., 1984.

22. W. E. Pennell, Martin Marietta Energy Systems, Inc., Oak Ridge Nat1. Lab., 'HeavySection Steel Technology Program - Fracture Issues - Heavy-Section Steel Technology Program," Proc. of the I7th Water Reactor Safety Information Meeting, USNRC Report NUREG/CP-0105, Vol. 3, March 1990.

23. S. T. Rolfe and J. M. Barsom, Fracture and Fatigue Control In Structures, Prentice-Hall, Inc., Englewood Cliffs, New Jersey, 1977.

24. S. J. Garwood and T. G. Davey, "Behavior of A533B Under Biaxial Loading at $+70^{\circ} \mathrm{C}$," Int. J. Pres. Ves. Piping 36, pp. 199-224, 1989. 
25. S. J. Garwood, T. G. Davey, and Y. C. Wong, "The effect of Biaxial Loading on A533B in the Ductile/Brittle Transition," presented at 21st National Symposium on Fracture Mechanics, Annapolis, Md., June 28-30, 1988.

26. T. L. Dickson, R. D. Cheverton, and D. K. M. Shum, Martin Marietta Energy Systems, Inc., Oak Ridge Natl. Lab., Inclusion of Unstable Ductile Tearing and Extrapolated CrackArrest Toughness Date in PWR Vessel Integrity Assessment, USNRC Report NUREG/CR-5473 (ORNL/TM-11450), May 1990.

27. R. H. Bryan et al., Martin Marietta Energy Systems, Inc., Oak Ridge Natl. Lab., Pressurized-Thermal-Shock Test of 6-in.-Thick Pressure Vessels. PTSE-2: Investigation of Low-Tearing Resistance and Warm Prestressing, USNRC Report NUREG/CR-4888 (ORNL-6377), December 1987.

28. J. G. Merkle, Martin Marietta Energy Systems, Inc., Oak Ridge Natl. Lab., An Overview of the Low Upper-Shelf Toughness Safety Margin Issue, USNRC Report NUREG/CR5552 (OR NL/TM-11314), August 1990.

29. T. L. Dickson, Martin Marietta Energy Systems, Inc., Oak Ridge Natl. Lab.,"Inclusion of Unstable Ductile Tearing and Extrapolated Crack Arrest Toughness Data in PWR Integrity Assessment," in Fatigue, Degradation and Fracture - 1990. edited by W. H. Bamford et al., PVP Vol. 195, pp. 127-136,ASME Pressure Vessel and Piping Conference, Nashville, Tenn., June 17-21, 1990.

30. W. R. Corwin et al., Martin Marietta Energy Systems, Inc., Oak Ridge Natl. Lab., Effects of Stainless Steel Weld Overlay Cladding on the Structural Integrity of Flawed Steel Plates in Bending, Series 1, USRNC Report NUREG/CR-4015 (ORNL/TM-9390), April 1985.

31. W. E. Pennell, Martin Marietta Energy Systems, Inc., Oak Ridge Natl. Lab., "ORNL Foreign Trip Report," ORNL/FTR-3185, April 1990. 

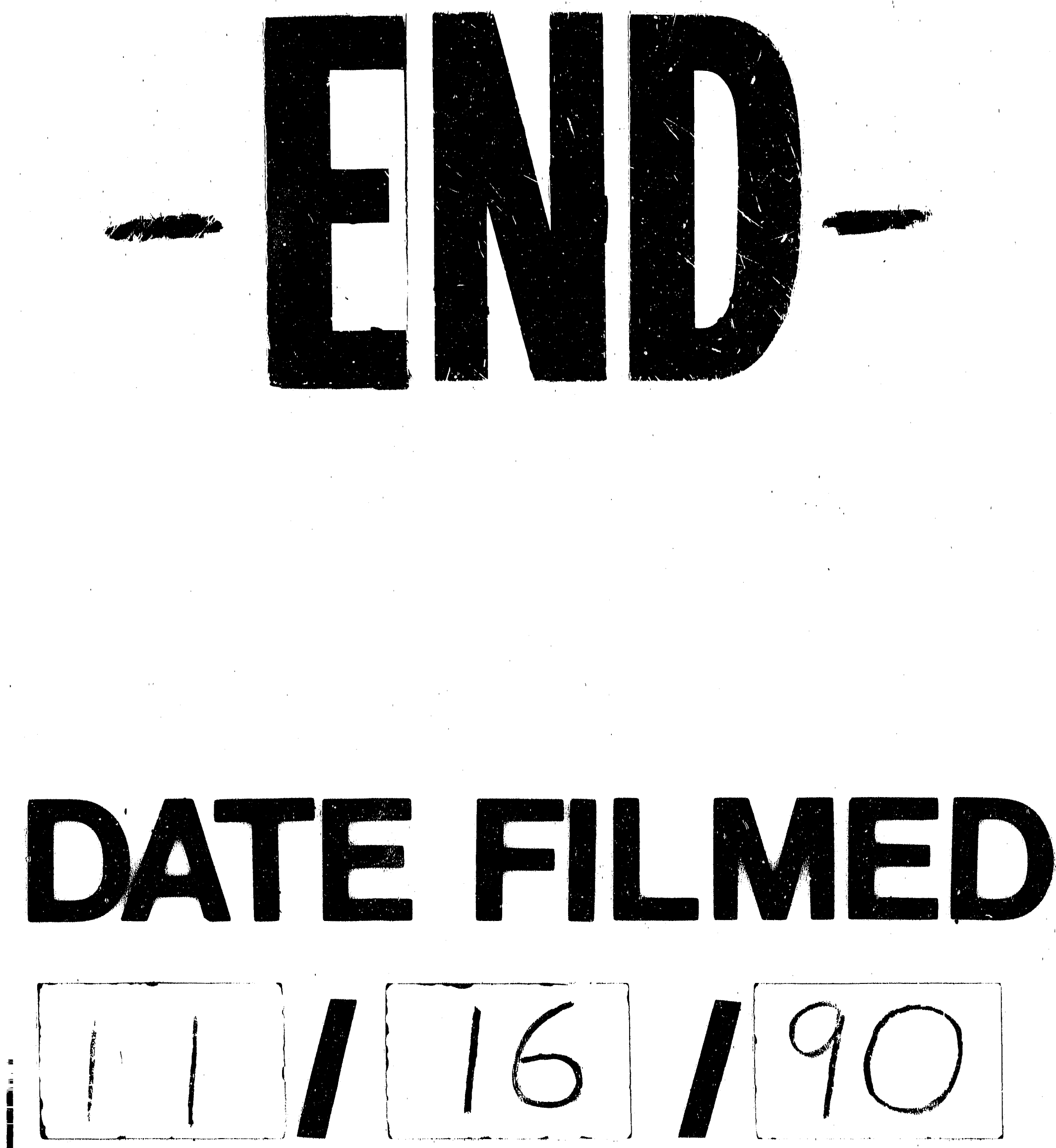
